\title{
Automatic approach for increasing the location accuracy of slow-moving landslide endogenous seismicity: the APOLoc method
}

\author{
F. Provost, ${ }^{1}$ J.-P. Malet, ${ }^{1}$ J. Gance, ${ }^{1,2}$ A. Helmstetter ${ }^{3}$ and C. Doubre ${ }^{1}$ \\ ${ }^{1}$ Institut de Physique du Globe de Strasbourg, CNRS UMR 7516, EOST, Université de Strasbourg, 5 rue Descartes, F-67084 Strasbourg Cedex, France. \\ E-mail:f.provost@unistra.fr \\ ${ }^{2}$ IRIS-Instruments, 1 Avenue Buffon, F-45100 Orléans, France \\ ${ }^{3}$ ISTerre, Université Grenoble Alpes, CNRS UMR7265, F-38400 Saint-Martin d'Hères, France
}

Accepted 2018 August 8. Received 2018 August 6; in original form 2017 August 08

\begin{abstract}
S U M MAR Y
Seismological observations offer valuable insights on the stress-strain states, the physical mechanisms and the possible precursory signs of activation of various Earth surface processes (i.e. volcanoes, glaciers and landslides). Comprehensive catalogues of the endogenous landslide seismicity, that is corresponding to seismic sources generated by the unstable slope from either mechanical or hydrological origins, should include the typology and an estimate of the source parameters (location, magnitude) of the event. These advanced catalogues constitute a strong basis to better describe the slope deformation and its time evolution and better understand the controlling factors. Because the number of seismic events in landslide catalogues is generally large, automatic approaches must be considered for defining both the typology and the location of the sources. We propose here a new location approach called Automatic Picking Optimization and Location method-APOLoc for locating landslide endogenous seismic sources from seismological arrays located at close distance. The approach is based on the automatic picking of the $P$ waves arrivals by optimizing the intertrace correlations. The method is tested on calibration shots realized at the Super-Sauze landslide (Southeast French Alps) and compared to other location approaches. By using a realistic velocity model obtained from a seismic tomography campaign, APOLOC reduces the epicentre errors to $23 \mathrm{~m}$ (on average) compared to $c a .40 \mathrm{~m}$ for the other approaches. APOLoc is then applied for documenting the endogenous seismicity (i.e. slopequakes and rockfalls) at the landslide.
\end{abstract}

Key words: Landslide seismology; Micro-seismic sources; Automatic picking; Automatic location; Beam-Forming.

\section{INTRODUCTION}

The term landslide refers to a large range of gravitational instabilities of various sizes, rheologies and dynamics. They may be triggered by internal causes, such as changes of pore-fluid pressure due to gravitational load and/or external causes such as heavy and prolonged rainfalls or earthquakes. Current forecasting methods are based on a prediction of the failure or acceleration of the mass from geodetic (Saito 1969; Petley 2004), hydrologic and/or meteorological data (Bernardie et al. 2015). In most cases, these statistical methods fail in providing an accurate timing of the failure (Intrieri \& Gigli 2016) as many physical mechanisms can also interact and initiate slope acceleration and slope failure depending on the geomechanical properties of the mass. Slope acceleration towards failure results from fracture propagation at depth (Crosta \& Agliardi 2003; Amitrano et al. 2005; Petley et al. 2005; Yamada et al. 2016; Poli 2017) or from rheological solid-fluid transition (Van Asch 1984;
Malet 2003; van Asch et al. 2006; Mainsant et al. 2012b; Carrière et al. 2018). These processes generate seismic signatures that can be investigated.

Two main approaches exist to analyse the seismic signals recorded on unstable slopes: microseismic or seismic noise correlation monitoring (Amitrano et al. 2005; Larose 2017). Seismic noise correlation monitoring computes the variation of the shear waves velocity in the medium through time. The shear waves are related to the shear modulus of the medium and their variation may reflect changes in the mechanical properties of the mass. The method seems to be particularly efficient for the monitoring of soil fluidization. A drop in the shear waves velocity has been observed before acceleration of the Pont-Bourquin mudflow (Switzerland; Mainsant et al. 2012b) and have been reproduced in laboratory experiments for clayey soils (Mainsant et al. 2012a, 2015). Microseismic monitoring aims at detecting and classifying the seismic sources generated by landslide deformation. The analysis of the 
space and time distribution of the sources allows retrieving the mechanism of the seismic sources in order to improve the knowledge on the mechanical state of the landslide. It is also a valuable information to understand the temporal response of the slopes to external forcings. Catalogues of landslide seismic activity constitute an efficient corpus of information to forecast the evolution of slope deformation, and to understand the temporal response of the slopes to external forcings. As precursory events have been detected before a few large failures, the creation of automatic catalogues documenting the long-term landslide seismic activity is needed to improve the prediction of slope deformation. Seismological precursory signals have been recorded on a coastal cliff before its collapse (Amitrano et al. 2005) and before some major landslides (Caplan-Auerbach \& Huggel 2007; Yamada et al. 2016; Poli 2017; Schöpa et al. 2017) demonstrating the potential of seismology as an input for warning systems. Detection and location of the seismic signals in real-time has demonstrated its efficiency on volcanoes to provide alarms before eruption (Chouet et al. 1994; García et al. 2014). Thus, one of the challenge for developing robust landslide monitoring and warning systems integrating seismic observations is the automatic creation of advanced seismic catalogues including the detection, the location and the characterization of the endogenous seismic signals.

Previous analyses of landslide microseismicity revealed the occurrence of endogenous seismic sources in both brittle [e.g. rockslides; Amitrano et al. (2005); Spillmann et al. (2007); Helmstetter \& Garambois (2010); Levy et al. (2011); Walter et al. (2012); Brückl et al. (2013); Provost et al. (2018)] and ductile medium [e.g. earth/mudslides; Rouse et al. (1991); Gomberg et al. (1995); Tonnellier et al. (2013); Walter et al. (2013); Provost et al. (2018)]. However the mechanisms controlling the generation of these seismic signals remain poorly understood, mainly because of the poor accuracy of the seismic source location with respect to the landslide dimensions. Accurate source location for landslides is complex due to:

(1) The difficulty in constructing reliable velocity models taking into account the spatial and temporal variations of the petrophysical properties of the medium.

(2) The complexity of the seismic signals, particularly for the identification of $P$ and $S$ waves (Spillmann et al. 2007; Lacroix \& Helmstetter 2011), due to low signal-to-noise ratios (SNR) resulting from low energy sources $\left(M_{\mathrm{L}}<0\right)$, high attenuation of the seismic waves in unconsolidated and cracked media (Rouse et al. 1991; Gance et al. 2012), and the short propagation distances and possible scattering.

(3) The field conditions (steep slopes, rapidly evolving surface topography, often in mountain areas with difficult meteorological conditions) rendering the maintenance of seismic instruments difficult for long-term observations and potentially modifying signal polarities (Neuberg \& Pointer 2000).

The objective of this work is to propose an accurate location procedure for the automatic analysis of landslide endogenous seismic sources. The proposed method consists in a new coupled picking and location procedure: APOLoc (which stands for Automatic Picking Optimization and Location). After building a realistic velocity model for $P$ waves from seismic tomography profiles, the $A P O L O c$ workflow consists in three steps: first, the search area is constrained by applying an Amplitude Source Location analysis (ASL); second, the onset of the signal is automatically identified using a Kurtosis-based function; third, the picking of the signal onset is refined by recursively optimizing the intertrace correlation. APOLOC is tested on a set of 15 calibration shots and compared to other location methods: Amplitude Source Location [ASL; Taisne et al. (2011)], Probabilistic location [NonLinLoc; Lomax et al. (2000)] and Beam-Forming [BF; Lacroix \& Helmstetter (2011)]. The effect of the velocity model on the location accuracy is also tested and discussed for the calibration shots. These tests prove the efficiency of APOLOc combined to a realistic $P$-wave velocity model. Finally, this approach is applied to natural events (i.e. slopequakes and rockfalls) and its suitability is discussed.

\section{STUDY SITE: THE SUPER-SAUZE LANDSLIDE}

The study site is the Super-Sauze landslide located in the Southeast French Alps. The landslide is composed of reworked clay shales (black marls) of the Jurassic age. Triggered in the early 1960s, it has propagated progressively downslope and has reached a volume of $750000 \mathrm{~m}^{3}$ and a size of $800 \times 300 \mathrm{~m}^{2}$ with an average thickness of $15 \mathrm{~m}$. The landslide is one of the permanent monitoring sites of the French Landslide Observatory OMIV (Observatoire Multidisciplinaire des Instabilités de Versant: http://www.ano-omiv.cnrs.fr). Three categories of observations are monitored since 2007 using different sensors: the surface deformation monitored using permanent GPS, terrestrial optical cameras and repeated terrestrial laser scanning campaigns; the subsurface hydrology using a network of pore water pressure sensors installed in shallow piezometers and soil humidity probes; the seismic activity of the slope using two permanent arrays of seismometers . Geophysical and geotechnical investigation campaigns helped to constrain the underground structure (Malet 2003; Schmutz et al. 2009; Gance et al. 2012; Travelletti \& Malet 2012). Dynamic penetration tests and inclinometric measurements showed the presence of two main units above the bedrock (Malet 2003). The first and shallow unit, with an average thickness of 5-9 $\mathrm{m}$, can be subdivided into two sublayers depending on the water saturation of the medium. The top sublayer, with an average thickness of less than $5 \mathrm{~m}$, is the vadose (unsaturated) zone, mostly dry and characterized by a brittle behaviour; the lower 4-m-thick sublayer is the saturated zone characterized by a viscoplastic behavior (Malet 2003; Travelletti \& Malet 2012). A shear surface is identified at the bottom of this unit and is corresponding to the lower limit of the groundwater table (Malet 2003). The second and deep unit, not observed throughout the whole landslide (with an average thickness of 5-10 m), is an impermeable and very compact medium with a brittle behavior (Malet 2003). Underneath, the bedrock is composed of intact black marls (Malet et al. 2005; Travelletti \& Malet 2012). From GPS and remote sensing geodetic measures, the average surface displacement rates are in the range of $0.01-0.03 \mathrm{~m} \mathrm{~d}^{-1}$ but velocities up to $3.5 \mathrm{~m} \mathrm{~d}^{-1}$ can be reached during acceleration phases in springtime (Malet et al. 2005; Stumpf \& Kerle 2011; Stumpf et al. 2014). The upper part of the landslide is the most active part of the slope in terms of surface deformation (Stumpf et al. 2014, 2015) as well as for seismic activity (Walter et al. 2012; Tonnellier et al. 2013). Most of the deformation occurs around a stable buried bedrock crest (i.e. a protrusion of the bedrock) along two shallow mudflows (Fig. 1). Various modes of deformation are identified: a rigid deformation at the surface during the low velocity periods with the development of fissure networks in extension and shearing and at depth along the shear bands; a ductile deformation at the surface during periods of 


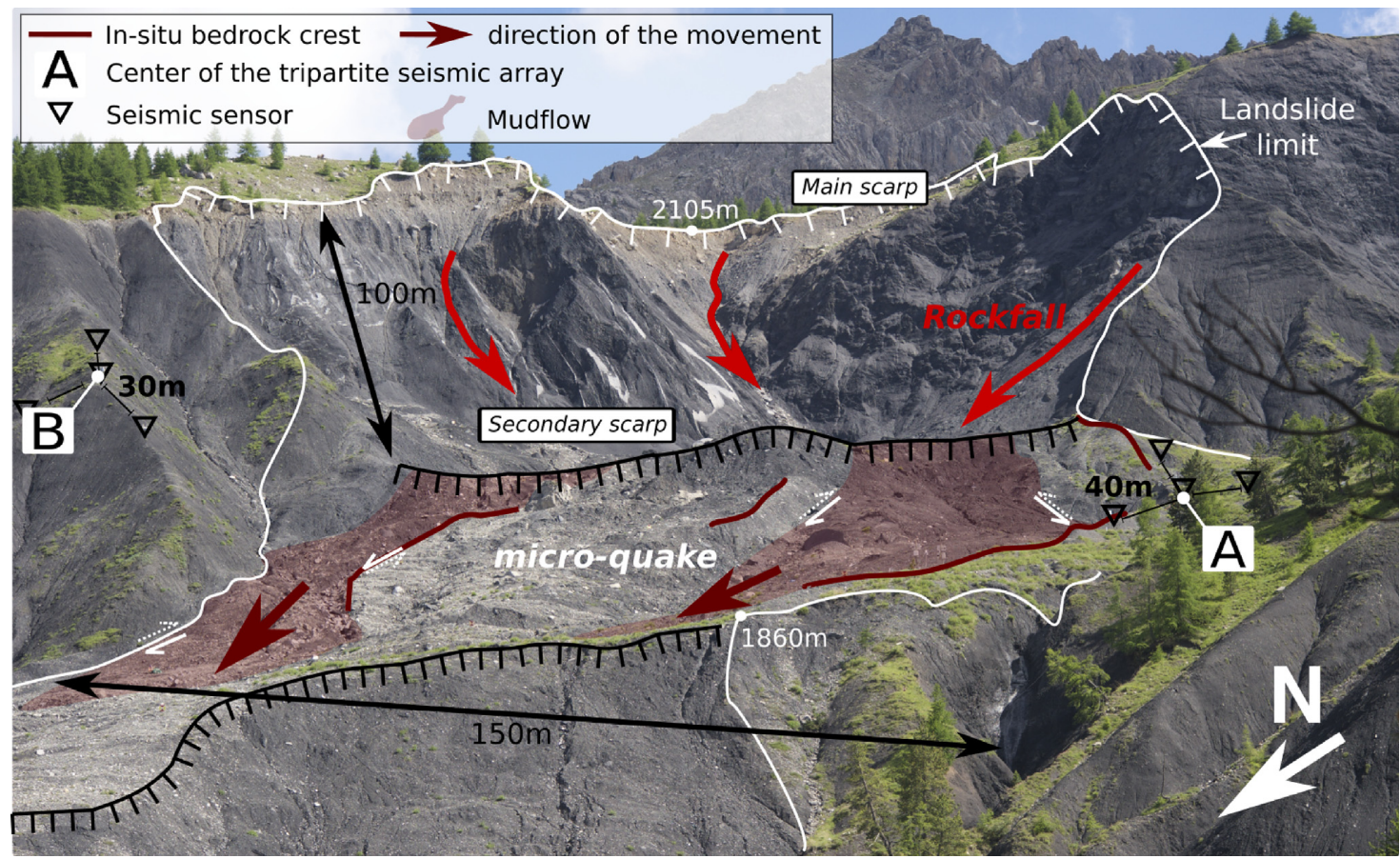

Figure 1. Morphology of the Super-Sauze landslide with indications on the dimensions, main geomorphological features and possible location of the endogenous seismic sources.

high velocity deformation with the progression of the material as a viscous fluid [e.g. shallow mudflows; Malet et al. (2005); van Asch et al. (2006)].

\section{DATA: GEOPHYSICAL STRUCTURE OF THE LANDSLIDE AND SEISMOLOGICAL OBSERVATIONS}

\subsection{Geophysical structure of the landslide: $P$-wave seismic model}

Prior to this investigation, four seismic profiles were measured on the landslide. They showed a complex distribution of the seismic velocity (Grandjean et al. 2006; Tonnellier et al. 2013; Gance et al. 2012). A dense coverage seismic campaign has been conducted in August 2014 in order to estimate the velocity structure at high spatial resolution. During this campaign, the sensors were installed along 12 profiles spaced of $c a .30 \mathrm{~m}$. and located in the upper part of the landslide [8 across-slope profiles and 4 along-slope profiles (Fig. 2)]. Along each profile, 48 vertical geophones were spaced by $5 \mathrm{~m}$, and the sources were shot every two geophones. The Quasi-Newton inversion approach developed by Gance et al. (2012) is used to estimate the $P$-wave velocity structure for each profile (Fig. 3). It takes the first Fresnel zone as an approximation of the Hessian matrix and uses the full source spectrum to reduce the tomography resolution. Gance et al. (2012) show its efficiency to invert complex velocity structures in highly heterogeneous medium. The final model is obtained by inverting only the picks with less than $5 \mathrm{~ms}$ of traveltime residuals (Gance et al. 2012). The RMS error ranges from 1.6 to $3.5 \mathrm{~ms}$.

A 3-D seismic model is built by a cubic interpolation of the 2-D profiles on a regular grid of $5 \times 5 \times 5 \mathrm{~m}^{3}$ in order to keep low lateral velocity gradient. The model is then oversampled to cells of
$1 \times 1 \times 1 \mathrm{~m}^{3}$. Outside of the seismic tomography area, the $P$-wave velocity is set to $2700 \mathrm{~m} \mathrm{~s}^{-1}$ in the bedrock and to $600 \mathrm{~m} \mathrm{~s}^{-1}$ in the landslide body (Fig. 4). $P$-wave traveltime grids are computed with the Fast Marching Method (Podvin \& Lecomte 1991) implemented in the software NonLinLoc (Lomax et al. 2000). The Fast Marching Method (FMM) is a 3-D solver of the eikonal equation providing a solution of the seismic wave front propagation through a given velocity model. Grids of traveltimes are computed and further used for the location of the seismic sources.

\subsection{Microseismic monitoring and seismic signal description}

Seismological data are provided by OMIV - the French Landslide Observatory (RESIF/OMIV 2015). The seismicity of the landslide is continuously recorded by a single seismic array since 2009 (i.e. seismic array A, Fig. 1) and by two arrays since 2013 (i.e. seismic array B, Fig. 1). Each array corresponds to an equilateral triangle with three vertical seismometers distant from the central 3-component sensor of 40 and $30 \mathrm{~m}$ for the array A and the array B, respectively. The seismic array A is instrumented with Agecodagis Noemax sensors (natural frequency: $4.5 \mathrm{~Hz}$ ), the seismic array B is instrumented with Sercel L4C sensors (natural frequency: $1 \mathrm{~Hz}$ ). The sampling frequency for all sensors is $250 \mathrm{~Hz}$.

The seismic events can be classified in four main types (Walter et al. 2012; Tonnellier et al. 2013; Provost et al. 2017): (1) rockfalls, (2) slopequakes, (3) regional earthquakes/teleseisms and (4) anthropogenic/natural noise (i.e. car, engine, rainfall, water discharge in torrent, wind, thunderstorm). Most of the regional earthquakes recorded at the Super-Sauze slope originate from the active Sérennes fault located $10 \mathrm{~km}$ far from the landslide (Jenatton et al. 2007). The two first classes are considered as endogenous as they are generated by the slope deformation. The first type of endogenous signal is 

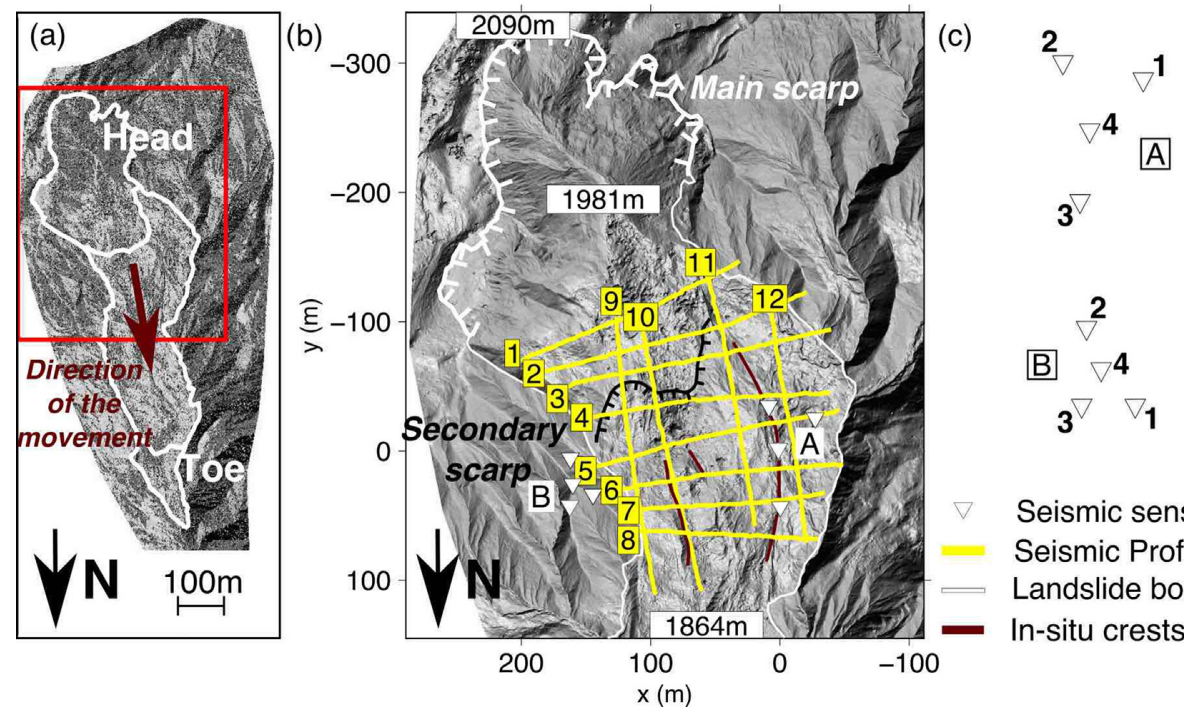

Seismic sensor

Seismic Profile

Landslide boundary

In-situ crests

Figure 2. Location of the permanent seismic network (e.g. seismic arrays A and B), and of the seismic tomography profiles: (a) investigated area within the landslide, (b) location of the sensors and seismic tomography profiles and (c) number and geometry of the sensors for the two arrays A and B.

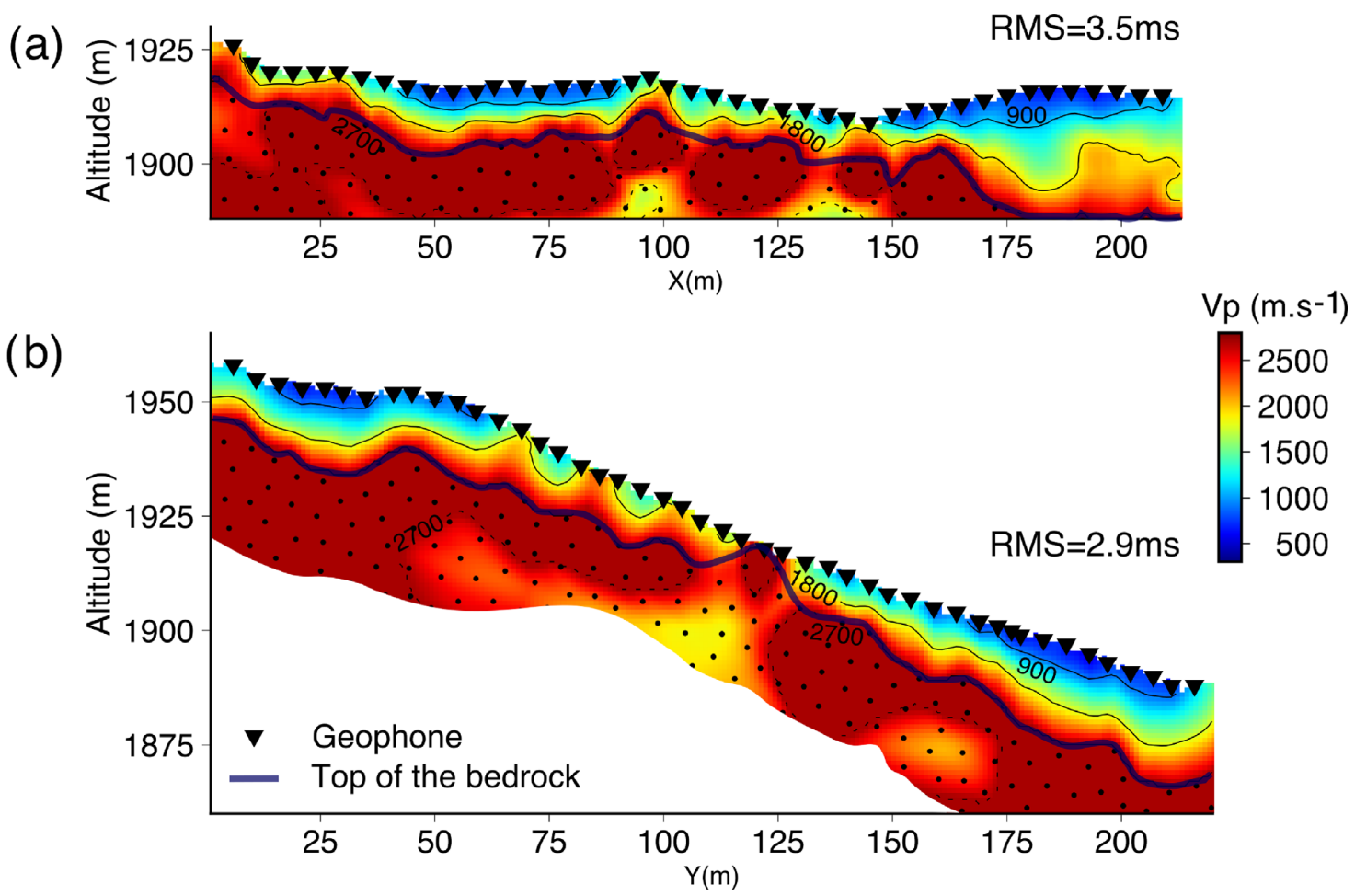

Figure 3. Inverted $P$-wave seismic velocity field for (a) profile 5 and (b) profile 11 . In the bedrock (areas with the dots), the velocity is assumed to be homogeneous $\left(v_{P}=2700 \mathrm{~m} \mathrm{~s}^{-1}\right)$.

generated by rockfalls of various sizes, from decimeter-scale debris to metre-scale large blocks. Their seismic signals present a series of impacts that are easily recognizable in the waveform as well as in the frequency content. The recorded signals last from five to tens of seconds and usually contain dominant frequencies in the $5-50 \mathrm{~Hz}$ range (Fig. 5). Most of these events are recorded by the two seismic arrays. Some $P$ waves onsets could be recognized if the successive impacts are clear and separated through time (Vilajosana et al. 2008). On the contrary, when the signals of the different impacts are overlapping, surface waves appear to dominate the recorded signals (Hibert et al. 2014; Bottelin et al. 2014; Levy et al. 2015). For some clear and separated impacts, $P$ waves are observed (Fig. 5c). However, the interpretation of the wave polarization remains difficult. Indeed, horizontally polarized $P$ waves are expected for shallow sources in complex topography (Neuberg \& Pointer 2000) as observed at the seismic array B (Fig. 5c.). The second type of endogenous signals is generated by slopequakes; these sources are assumed to result from stress release by both fracture opening or 

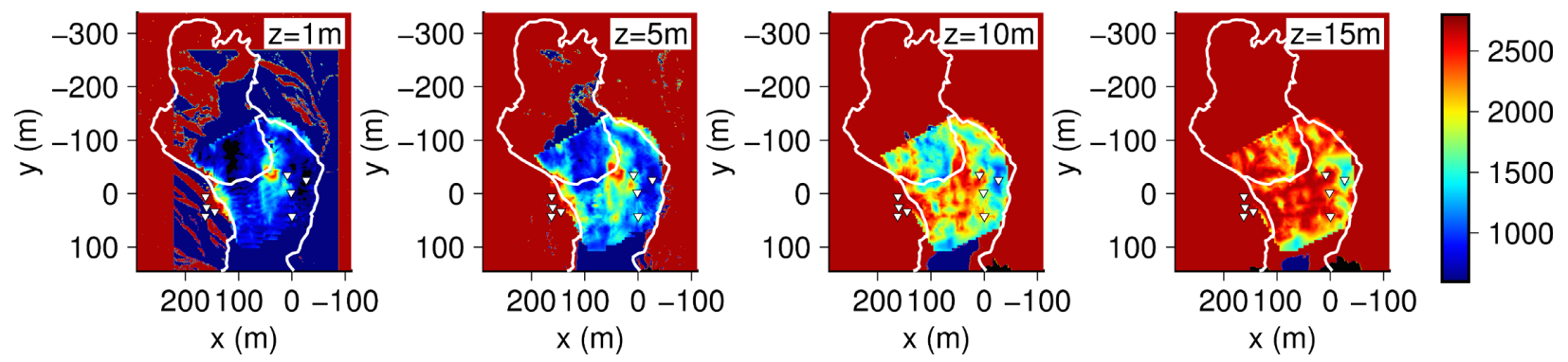

Figure 4. $P$-wave seismic velocity model at four depths $(Z=-1 \mathrm{~m}, Z=-5 \mathrm{~m}, Z=-10 \mathrm{~m}, Z=-15 \mathrm{~m})$. The reference $Z=0 \mathrm{~m}$ is the topographic surface.

(a)
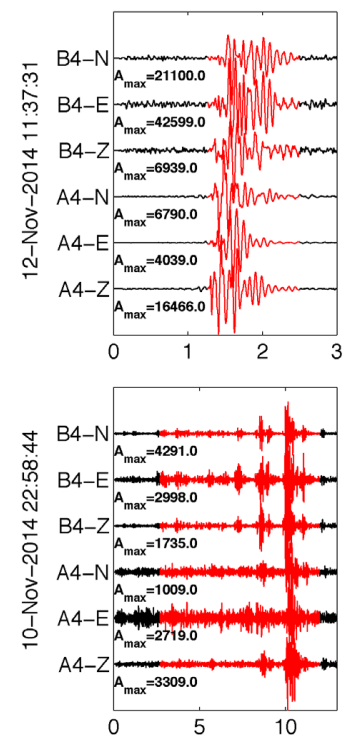

(b)
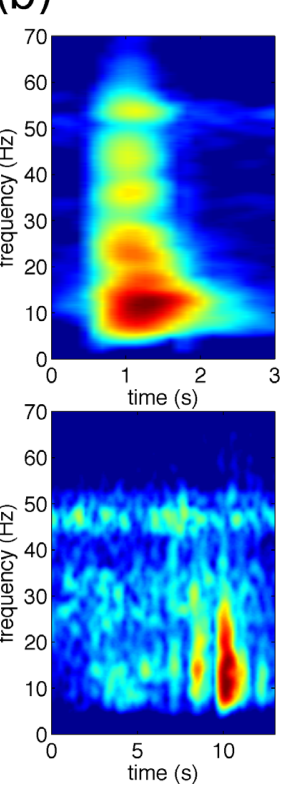

(c)
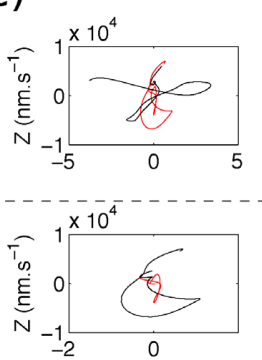
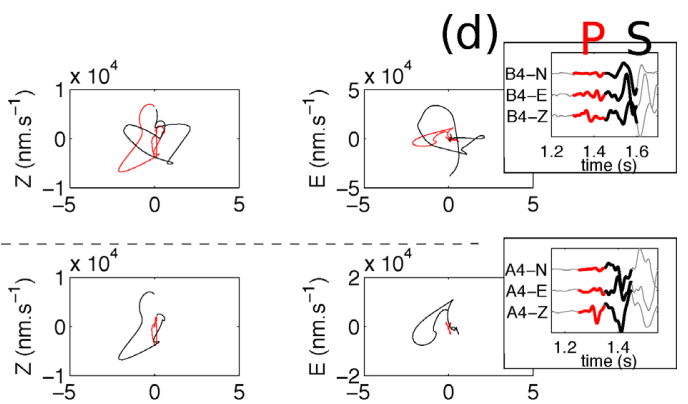
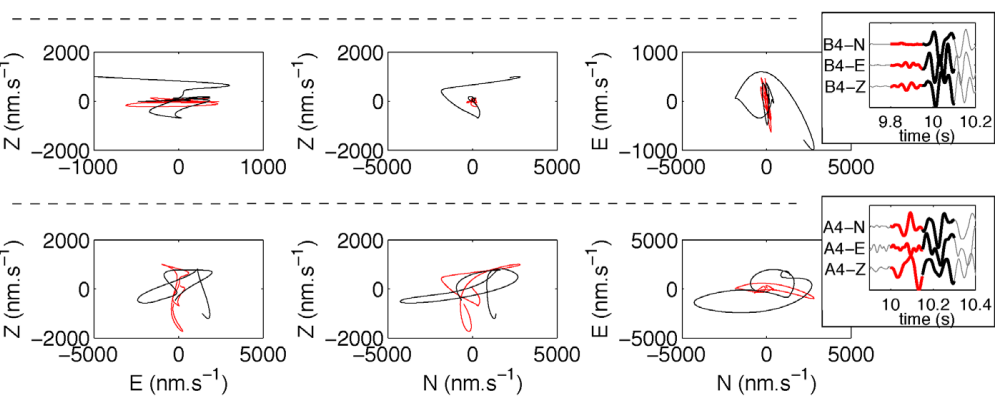

Figure 5. Example of endogenous seismic sources recorded at the Super-Sauze landslide: typical slopequakes with high-frequency content (top) and typical rockfall event (bottom). The figure displays (a) the waveform recorded at the three component sensor of each seismic array with the maximal amplitude (A $A_{m a x}$ in $\mathrm{nm} \mathrm{s}^{-1}$ ), (b) the spectrogram of the signal, (c) the polarization of the $P$ waves (red) and surface waves (black) and (d) the waveforms of the signal onset with the corresponding $\underline{\mathrm{P}}$ - and surface waves windows. Their polarization is vertical at seismic array A and horizontal at seismic array B for the example displayed in Fig. 5.

shearing (Helmstetter \& Garambois 2010; Walter et al. 2013; Tonnellier et al. 2013; Vouillamoz et al. 2017; Provost et al. 2018). The recorded signals last less than $5 \mathrm{~s}$ and different waveforms and frequency content may be observed (Provost et al. 2018). It must be noted that some events are only recorded by one of the seismic arrays (Walter et al. 2012; Tonnellier et al. 2013; Vouillamoz et al. 2017) and that the intertrace correlation of the whole signal is low due to scattering and dispersion of the seismic waves (Walter et al. 2012; Tonnellier et al. 2013). $P$-wave arrivals of most of the slopequakes are identifiable on the seismic signal vertical component (Fig. 5). The observation data set consists of three acquisition periods from 2013 October 11 to November 19, from 2014 November 10 to 30, and from 2015 June 9 to August 15. The investigated data set consists of 418 rockfall events and 239 slopequake events that have been classified manually. The original purpose of this catalogue was to train an automatic machine learning classifier (Provost et al. 2017). The duration of this data set is too short to analyse the dynamics of the landslide but allows us to test the suitability of the proposed location method on natural events.

\section{METHOD: APOLoc, AUTOMATIC PICKING OPTIMIZATION AND LOCATION}

The picking of the phase onsets is a critical part of the location and is very challenging in the case of landslides because of the proximity of the sources to the sensors and the attenuation of the media. Prior investigation of the problem underlines the importance of the picking error for seismic source location at the Super-Sauze landslide (Appendix A). The proposed location method is based on a robust and automatic processing of the signal to obtain the picking time of the $P$-wave arrivals taking advantage of the 3 -D velocity model constructed from the seismic profiles. The strategy consists in (1) a pre-location of the source with the Amplitude Source Location (ASL) approach to reduce the grid search extension, (2) an automatic picking of the signal onset with a Kurtosis-based algorithm to broadly identify the onset of the signal, and (3) an iterative improvement of the picking based on the intertrace correlation maximization through picking time perturbation. The workflow of the method is presented in Fig. 6; the successive steps are detailed below. 

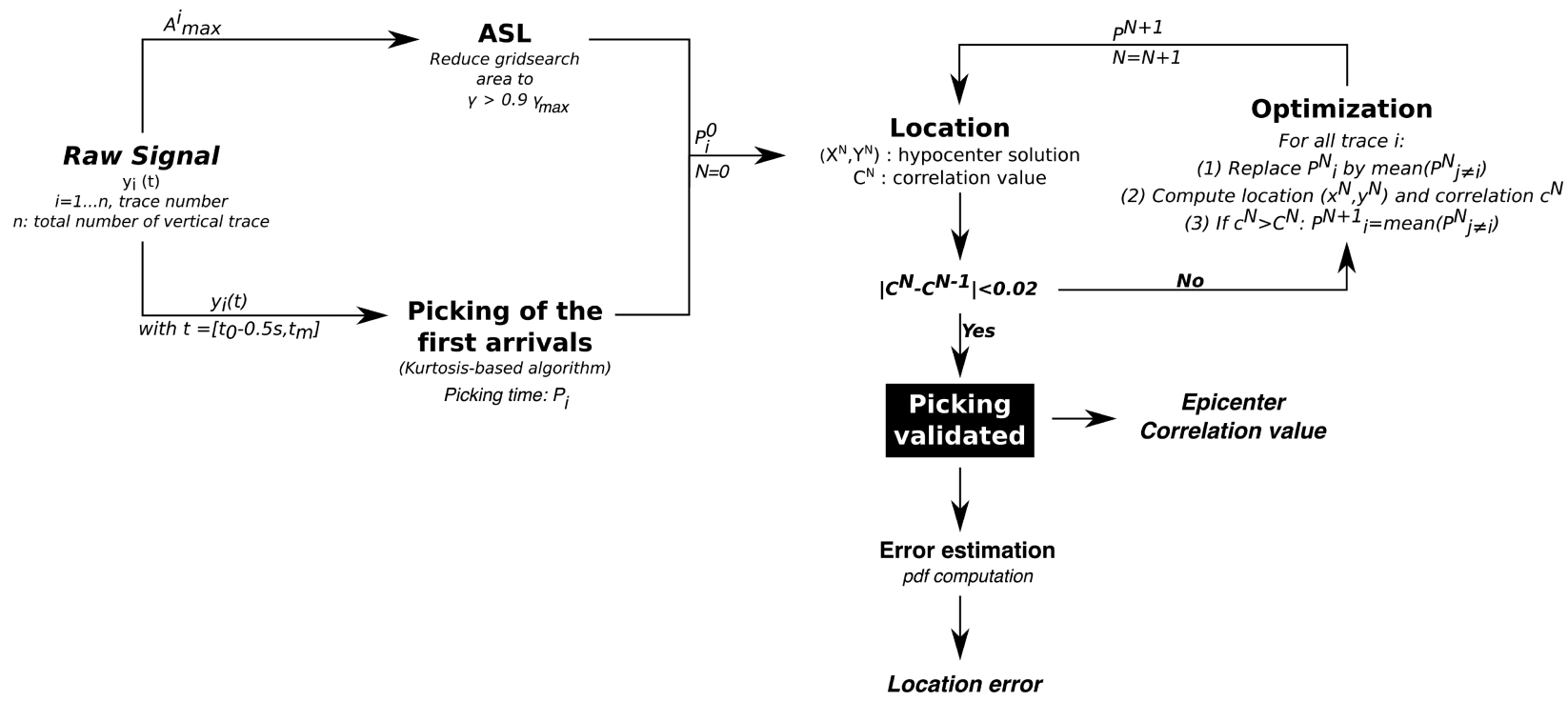

Figure 6. Flowchart of the proposed methodology.

\subsection{Initial location with signal amplitude analysis}

The grid search area is reduced by determining a rough location of the seismic source using the ASL method. The ASL method is classically used in volcanic environments to determine the location of seismic swarms during eruptions (Battaglia et al. 2003; Taisne et al. 2011) and has been more recently implemented for the location of debris-flows (Walter et al. 2017). The surface waves are used because they are more energetic than the $P$ waves and are likely recorded by most of the sensors. The amplitude of the seismic signals is modeled by a simple attenuation law for spherical waves (Battaglia et al. 2003):

$A(r)=A_{0} \frac{e^{-\alpha r}}{r^{n}}$,

where $A_{0}, \alpha, r$ are the amplitude of the seismic waves at the source, the attenuation coefficient depending of the media properties and the source-sensor distance, respectively. The exponent $n$ is equal to 0.5 for surface waves and equal to 1 for body waves (Taisne et al. 2011). The amplitude ratios are computed for each sensor pair $(i, j)$ and compared to the observed amplitude ratios. A misfit function (Taisne et al. 2011) is used:

$\gamma=1-\sqrt{\sum_{i} \sum_{j>i}\left(\frac{A_{i}^{\text {mod }}}{A_{j}^{\text {mod }}}-\frac{A_{i}^{o b s}}{A_{j}^{o b s}}\right)^{2}}$

The grid search area is reduced to the points satisfying the condition $: \gamma>0.9 \gamma_{\max }$.

\subsection{Initial picking of the signal onset}

The picks of the first arrivals $\left(\mathrm{P}_{K}\right)$ are identified using the Kurtosis method (Baillard et al. 2014; Hibert et al. 2014) which is the most suitable method for picking emergent arrivals of microseismic sources. As demonstrated for rockfalls at the Piton de la Fournaise volcano (Hibert et al. 2014), differences between manual and automatic picks are in the range of $0.05-0.30$ s for SNR $>10$ and SNR $<5$, respectively.

\subsection{Location procedure}

The location is determined by maximizing the intertrace correlation of the $P$-wave arrivals. The initial picking times determined by the Kurtosis function $\left(\mathrm{P}_{\text {Kurt }}\right)$ define the centre of the time window used for the computation of the intertrace correlation. We work with a time window of $\pm 0.16 \mathrm{~s}$ around the Kurtosis picked times $\left(\mathrm{P}_{\text {Kurt }}\right)$. To determine the epicentre location, the intertrace correlation is computed on this time window for each cell of the grid search area (cf. Section 5.1.1). The intertrace correlation values are calculated in the cell $(X, Y)$ :

$C(X, Y)=\frac{1}{N^{2}} \sum_{i, j} c_{i j} c_{i j}^{\max }$

$c_{i j}^{\max }$ is the maximum correlation of the traces $i$ and $j$ :

$c_{i j}^{\max }=\max _{\tau}\left(\frac{1}{\sigma_{x} \sigma_{y}} \int_{t_{0}-\delta_{t} / 2}^{t_{0}+\delta_{t} / 2} y_{i}(t) y_{j}(t-\tau) \mathrm{d} t\right)$.

The epicentre location is given by the point where the sum of the intertrace correlations is maximized. The intertrace correlation value differs from the one proposed by Lacroix \& Helmstetter (2011) since the weight values are not set as a function of the sensor to sensor distances but as a function of the maximum cross-correlation of the traces for the selected window. The weight of the traces for which the signals correlate are hence increased. A first location $\left(X_{0}\right.$, $Y_{0}$ ) and a new piking time $P_{0}=P_{K u r t}+\tau_{c_{\max }}$ is determined at the end of this step.

\subsection{Iterative improvement of the picking time}

The initial picking time $\left(\mathrm{P}_{\text {Kurt }}\right)$ can be incorrect for two reasons: (1) the Kurtosis-based algorithm may detect the first onset but may not pick the same part of the onset phase, and/or (2) the Kurtosis-based algorithm may significantly fail to detect the signal onset.

In order to pick the same part of the signal onset and reduce outliers, the centre of the time window $\left(\mathrm{P}^{N}\right)$ for each trace is iteratively improved. The picking time centre of the trace $i$ is successively replaced by the mean of the other picked times centre $(j \neq i)$. The previous location procedure is computed on the new window. If the intertrace correlation increases by changing the picking time of 
trace $i$, the picking time is replaced by the mean picked time of the other traces.

$P_{i}^{N+1}=\operatorname{mean}_{j \neq i}\left(P_{j}^{N}\right)$, if $c^{N}>C^{N}$

with $c^{N}$, the maximum intertrace correlation value for the tested change of piking time reference and $C^{N}$, the maximum intertrace correlation value obtained at the previous step $N$. This is repeated until the $\left|C_{N}-C_{N-1}\right|$ becomes lower than 0.02 with $N$ the number of iterations. At the end of this step, the epicentre location $(\mathrm{X}, \mathrm{Y})$ and the final picking times $\mathrm{P}^{\mathrm{fin}}$ are determined by maximizing the intercorrelation on the last optimized time window (i.e. centred on $\left.\mathrm{P}^{N}\right)$.

\subsection{Error estimation}

The location error is computed by estimating the Posterior Density Function (PDF) of the final picked arrival times. The errors on the location are computed with (Tarantola \& Valette 1982):

$P D F(X, Y)=\sum_{m=1}^{M} \exp \left(-\frac{1}{2 \sigma_{m}^{2}}\left(\Delta t_{m}^{o b s}-\Delta t_{m}^{m o d}\right)^{2}\right.$,

where $M$ is the number of sensor pairs, $\Delta t_{m}=P_{N}^{i}-t_{N}^{j}$ is the final picking time difference between the sensors $i$ and $j$, and $\sigma_{m}$ is the uncertainty of the picking. The choice of $\sigma_{m}$ is discussed in the next part. The prior probability is taken uniform and we do not estimate velocity model uncertainties.

\section{RESULTS}

\subsection{Validation of $A P O L o c$}

The methodology is tested for the location of 15 air-gun calibration shots. The timing of the shots was recorded with an accuracy of $1 \mathrm{~s}$ and their locations were measured with a GPS survey with an accuracy of $5 \mathrm{~cm}$. The locations of the shots cover the study area (Fig. 7). The data are filtered in the range of [5-100] Hz and the Kurtosis-based algorithm is computed on a time window ranging from $\left[\mathrm{t}_{0}-0.5 \mathrm{~s}-\mathrm{t}_{m}\right], t_{0}$ and $\mathrm{t}_{m}$ corresponding to the beginning of the signal defined by the spectrogram analysis and to the time of the maximum energy of the spectrogram, respectively. The amplitude analysis is carried out with the maximum amplitudes and the exponent is fixed equal to 0.5 assuming that the surface waves are the most energetic ones. The attenuation coefficient $\alpha$ used in the ASL prelocation method is assumed uniform. It is determined by analysis of the results for different values of $\alpha$ ranging from 0 to $0.05 \mathrm{~m}^{-1}$ with an increment of $0.001 \mathrm{~m}^{-1}$. We found that a value between 0.007 and $0.011 \mathrm{~m}^{-1}$ provided similar and reliable estimation of the location of the calibration shots. We choose to work with $\alpha=0.008 \mathrm{~m}^{-1}$. The location of the calibration shots with the ASL method and the grid search areas for each shot are displayed in Fig. 7. Most of the pre-location areas include the true shot location or are very close $(<10 \mathrm{~m})$ except for shot 17 .

The locations of the calibration shots obtained with APOLOC are plotted in Fig. 8(a). The computed source locations are consistent with the real locations of the calibration shots: the mean epicentre error is $27 \mathrm{~m}$ with a minimal error of $3 \mathrm{~m}$ and a maximal error of $105 \mathrm{~m}$ (Table 1). Shots located within the seismic network are the most accurately located with a mean epicentre error of $7 \pm 4 \mathrm{~m}$. Outside the seismic network, the location errors are larger with a mean epicentre error of $37 \pm 31 \mathrm{~m}$. Except for the shots 15 and 7,
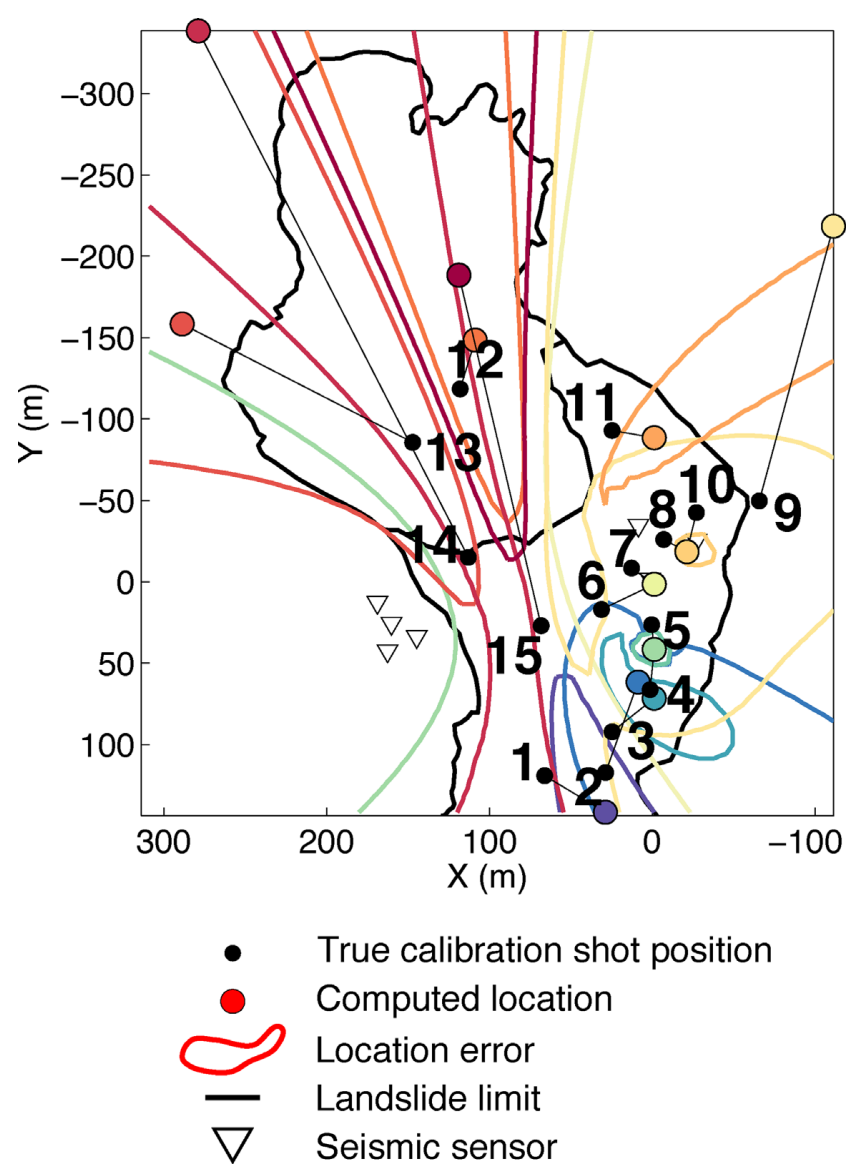

Figure 7. Location of the calibration shots with the ASL method and an attenuation coefficient $\alpha=0.008 \mathrm{~m}^{-1}$.

the first arrivals of the shots are recorded by only one of the seismic arrays with a high SNR. Despite the relatively small number of sensors used for the location $(<5)$, the epicentre errors are very small $(<10 \mathrm{~m})$ in the western part of the landslide (shots 2-11) while they are larger $([20-50] \mathrm{m})$ for shots located in the eastern part of the landslide (shots 1 and 12-14). The amplitude of the shot sources follows the attenuation law (Fig. 9) with $R^{2}$ value of 0.9741 . The attenuation coefficient is lower $\left(\alpha=0.002 \pm 0.03 \mathrm{~m}^{-1}\right)$ than the one used in pre-location step $\left(\alpha=0.008 \mathrm{~m}^{-1}\right)$. The attenuation coefficient is not well constrained since the lower and upper bound values are significantly large $(-0.033 ;+0.038)$.

The location results for the APOLoc method and for the manual picking are shown in Figs 9(b) and (c) and examples of the corresponding picked times are plotted in Fig. 10. A root-mean-square method is used to locate the shots from manual picked times; the epicentre of the source is the point that minimizes:

$R M S=\sqrt{\sum_{n=1}^{N} \frac{1}{N}\left(\delta t_{n}^{\text {obs }}-\delta t_{n}^{\text {mod }}\right)^{2}}$

with $N$ the number of pairs of sensors, $\delta t^{o b s}$ and $\delta t^{\text {mod }}$ the traveltime difference between the two sensors computed for manually picked and modeled arrival times, respectively. All the shots in the centre of the seismic array are precisely located with the three approaches. Outside the network, APOLOC provides better or equivalent results than the manual picking and the initial picking (i.e. $A P O L O c$ without optimization of the picking) except for shot 12. The correlation 
(a)

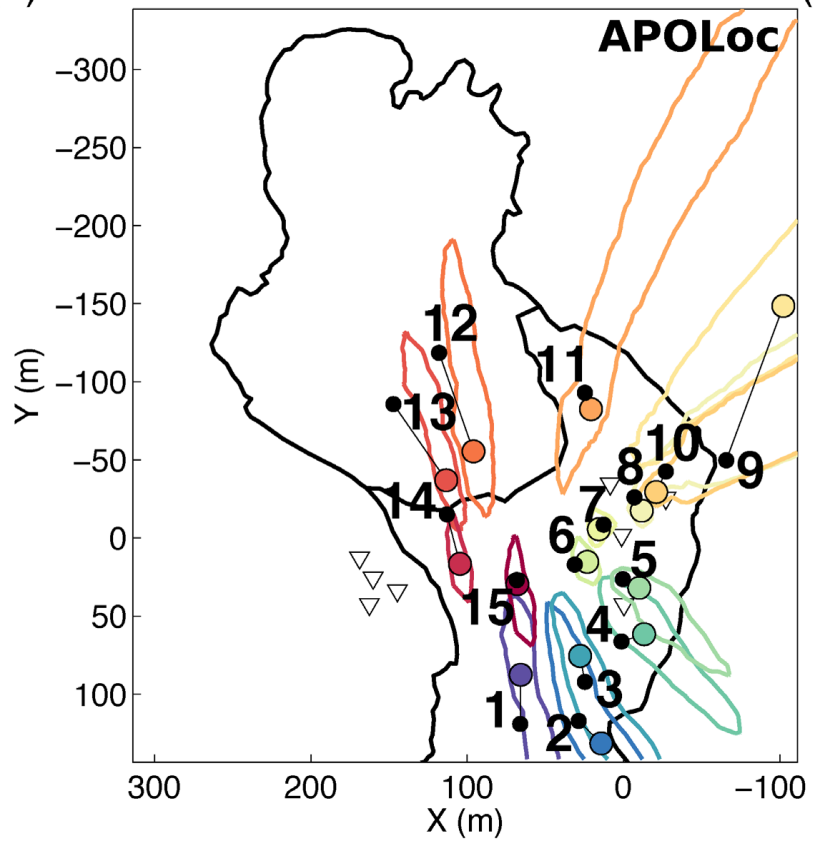

(b)

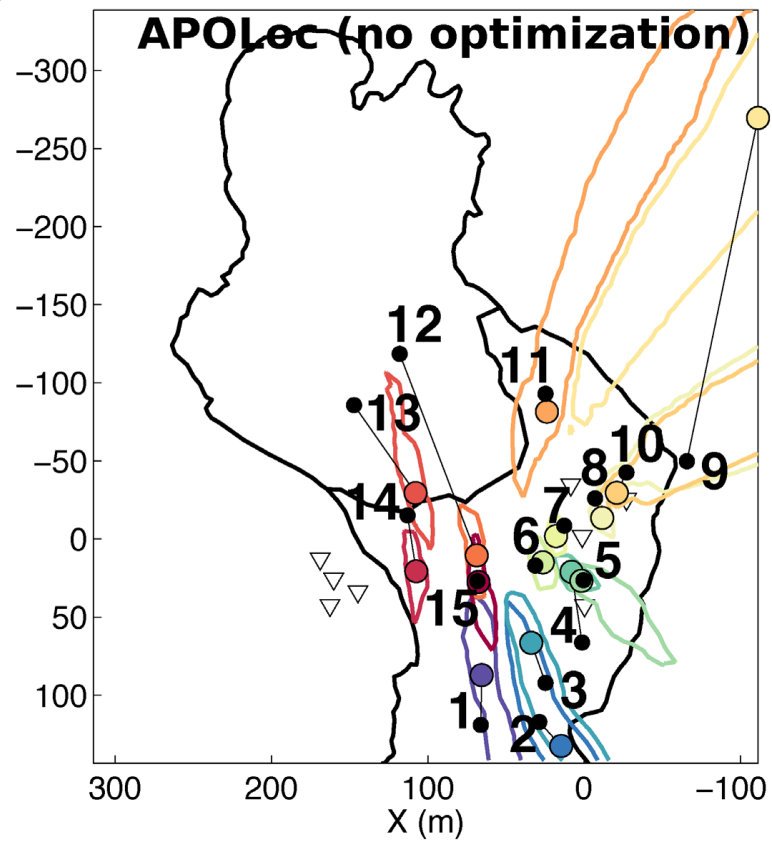

(c)
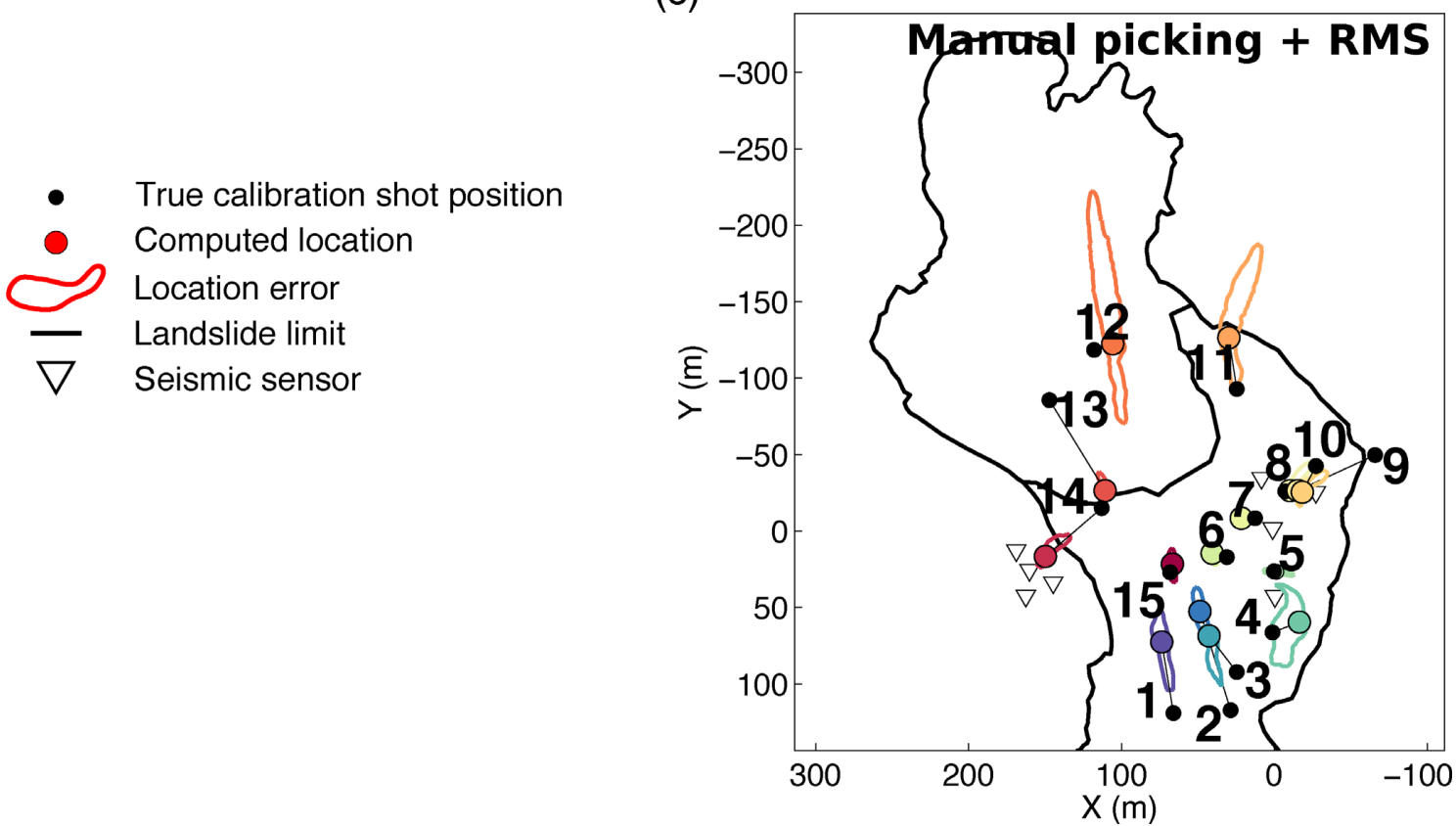

Figure 8. Location of the calibration shots with (a) the APOLOc method, (b) the APOLoc method without the optimization step and (c) the RMS location method with manually picked arrival times. For all the locations, the 3-D velocity model is used.

Table 1. Summary of the epicentre errors obtained for the different tests using three location methods: ASL, NonLinLoc, Beam-Forming and APOLoc. The latter is tested with and without the optimization of the picking and for several velocity models.

\begin{tabular}{|c|c|c|c|c|c|c|c|c|}
\hline Method & ASL & NonLinLoc & $\mathrm{BF}$ & & roposed method & Intertı & lation of $P$ & \\
\hline Model & l & $3-\mathrm{D}$ & $\mathrm{V}_{a p p}$ & $3-\mathrm{D}$ & $\begin{array}{c}\mathrm{V}_{P}=\underset{\mathrm{s}^{-1}}{2500 \mathrm{~m}} \\
\end{array}$ & $2 \mathrm{~L}$ & Gradient & $3-\mathrm{D}$ \\
\hline mean & 94 & 65 & 48 & 43 & 74 & 47 & 44 & 27 \\
\hline std & 112 & 65 & 36 & 61 & 61 & 67 & 37 & 29 \\
\hline
\end{tabular}




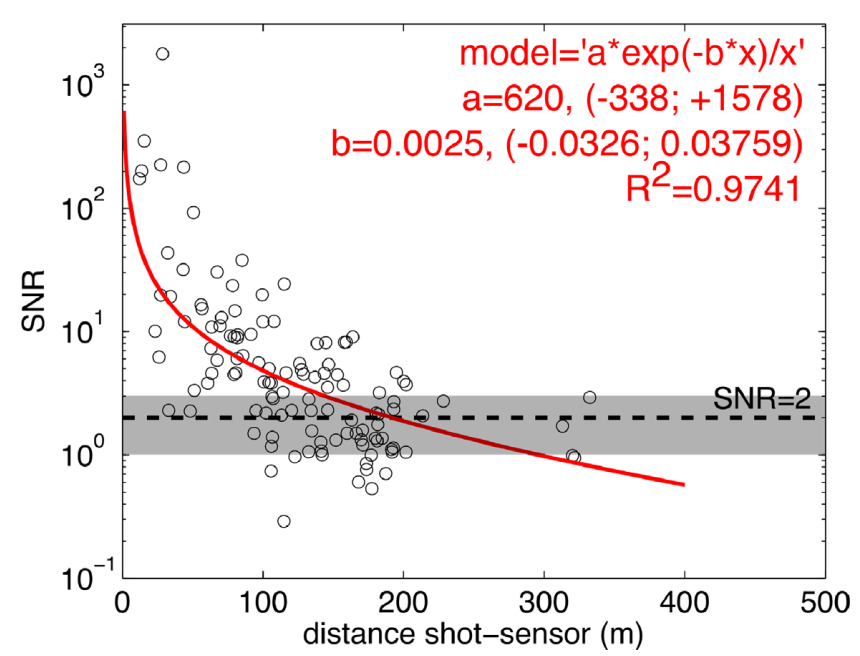

Figure 9. Signal-to-noise ratio (SNR) of the $P$-wave onset as a function of the source-sensor distance for the calibration shots. The red curves represent the regression function best-fitting the data. The equation of the model, the inverted coefficient with their upper and lower values and the regression coefficient are indicated in the upper right corner with ' $x$ ' the source-sensor distance.

values increase with the iterative optimization indicating a more robust estimate of the quality of the arrival times (mean correlation value of $C=0.22$ and $C=0.29$ without and with optimization, respectively). The optimization step demonstrates its efficiency to correct the initial picks (Fig. 10) and consequently, improves some source locations (Figs 9a and b).

The larger errors are observed for the shots outside the seismic array. The question is to determine whether this is due to picking errors or/and to velocity model errors. For shots 1, 3, 12, 13 and 14 , the difference between the final picking error and the model is larger than $0.01 \mathrm{~s}$ suggesting a velocity model error along these ray paths. A way to correct the velocity model inaccuracy is to add station correction (Spillmann et al. 2007; Lacroix \& Helmstetter 2011). This option was not tested here as the station correction is correlated to the azimuth and the distance of the shots preventing the estimate of a robust correction.

\subsection{Influence of the velocity model}

We tested the influence of the seismic velocity model. The shots are located with (1) a homogeneous velocity model $\left(\mathrm{v}_{p}=2500 \mathrm{~m}\right.$ $\mathrm{s}^{-1}$ ), (2) a 2-layer velocity model, (3) a gradient model and (4) a $3-D$ velocity model. For each of these models, traveltime tables are computed with the FMM algorithm. The results are plotted in Fig. 11. Among all the tested velocity models, the 3-D velocity model significantly decreases the mean epicentre error (Table 1). The 3-D velocity model constructed from the seismic tomography is thus considered as an accurate approximation of the velocity heterogeneity of the underground surface. We further carried out simulations to estimate the sensitivity of the location for the velocity models (Appendix A). The synthetic simulations show that the four seismic models are very similar to each other in terms of location of the synthetic sources; for real observations, they differ significantly when they are used as inputs to improve the picking of the $P$ wave. This last point demonstrates the difficulty to estimate the location error due to the velocity model uncertainties.

\subsection{Comparison to other location approaches}

Two other approaches are tested to locate the calibration shots: (1) the NonLinLoc approach (Lomax et al. 2000) with a manual picking and (2) the full waveform Beam-Forming approach with an inversion of the velocity (Lacroix \& Helmstetter 2011). Probabilistic estimation of the location from the manual picking of the $P$ waves provides large epicentre errors (mean epicentre error : $65 \mathrm{~m}$; Table 1, Fig. 12a). Most the epicentre locations are shifted towards the seismic array A. The location errors are large and fail at delimiting the areas where the shots were triggered. It shows that the location of seismic sources in the landslide is highly uncertain and that considering uniform prior information leads to unconstrained locations. In the contrary, the pre-location step in APOLoc has a prior information on the source location thus improving the determination of the source locations. The waveform Beam-forming approach provides larger epicentre errors than APOLOc (mean epicentre error $48 \mathrm{~m}$; Table 1, Fig. 12b). Shots located inside the seismic network (except shot 15) are shifted towards the seismic array B while those located outside the seismic network in the eastern part of the landslide are more accurately located than with APOLOC (shots 1, 12, 13 and 14) with a mean epicentre error of $27 \mathrm{~m}$ (48 m with APOLoc). It is likely due to the fact that surface waves are more energetic and hence recorded by the two seismic arrays.

\section{DISCUSSION}

\subsection{Relevance of APOLoc for landslide endogenous sources}

The APOLoc method is used to locate the 239 slopequake and 418 rockfall events observed at Super-Sauze landslide. The slopequakes are located with the same criteria as for the calibration shots; the rockfalls are located using a different strategy as several impacts of blocks are observed and the first one is rarely the most energetic. To determine the time window, the maximum energy of the spectrogram is detected. The part of the signal used for the picking optimization is in the window $t_{m}-1 s$ to $t_{m}$ (with being $t_{m}$ the time of the spectrogram maximum). The results are presented in Figs 13 and 14 . The mean correlation values for the location of, respectively, the slopequakes and the rockfalls, are respectively, $0.23 \pm 0.12$ and $0.19 \pm 0.1$; these values are slightly smaller than the correlation values obtained for the calibration shots.

Most of the slopequakes are located inside the seismic network (Fig. 13). Some clusters are located in the vicinity of sensors A1 and A3 $(<10 \mathrm{~m})$. Few sources are located in the upper part of the landslide. The shapes of the location error are elongated, as for the calibration shots, in the north-south direction for the sources located inside the seismic network. The two clusters of seismicity located around sensors A1 and A3 present location errors elongated along the east-west direction. The location of these signals is in accordance with the geomorphological observations. We probably record only the sources occurring in the vicinity of the sensors or inside the seismic network where APOLOC demonstrated the most accurate location. If we analysed the SNR distribution versus the distance to the source for each sensor, the attenuation law is respected with coefficient of regression of 0.98 (Fig. 15a). This tends to confirm the reliability of the location for this kind of sources although we cannot confirm these locations.

The rockfalls are mostly located at the main scarp (Fig. 14). The shapes of the location errors are elongated along the northsouth direction and cover the whole area of the main scarp due to 
Shot 1
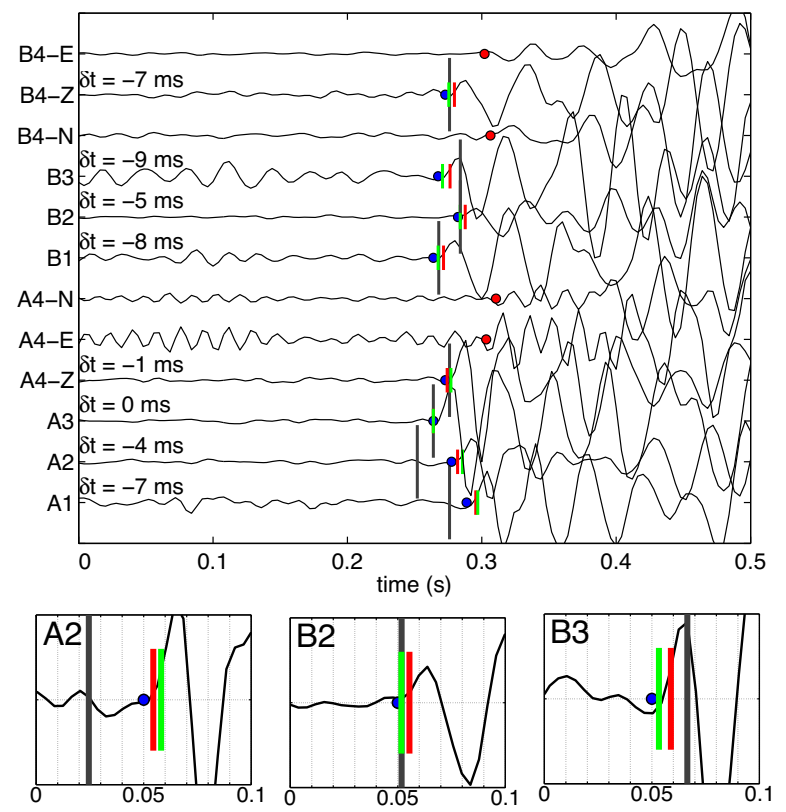

Shot 12
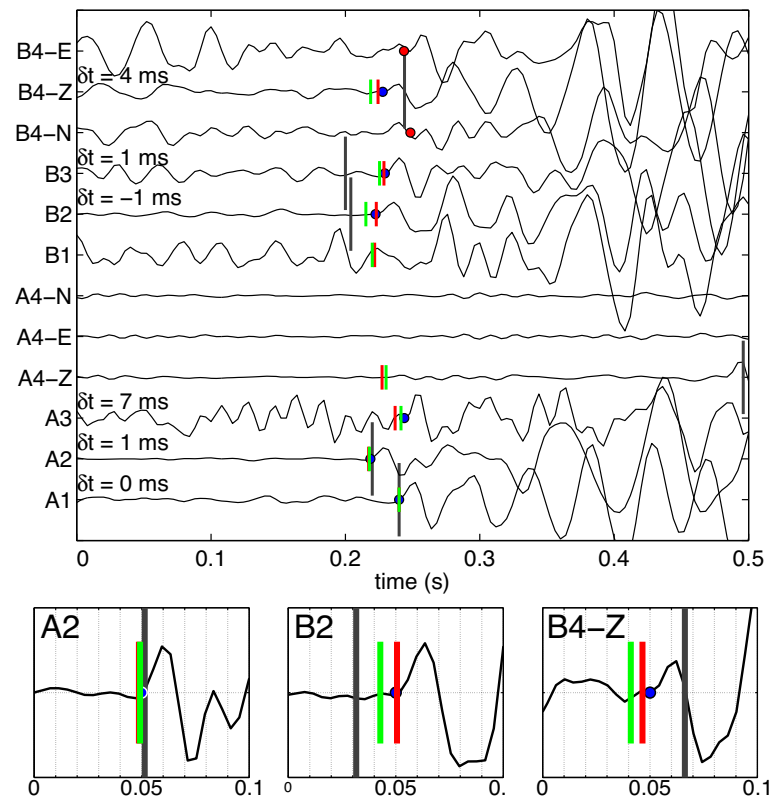

Shot 4
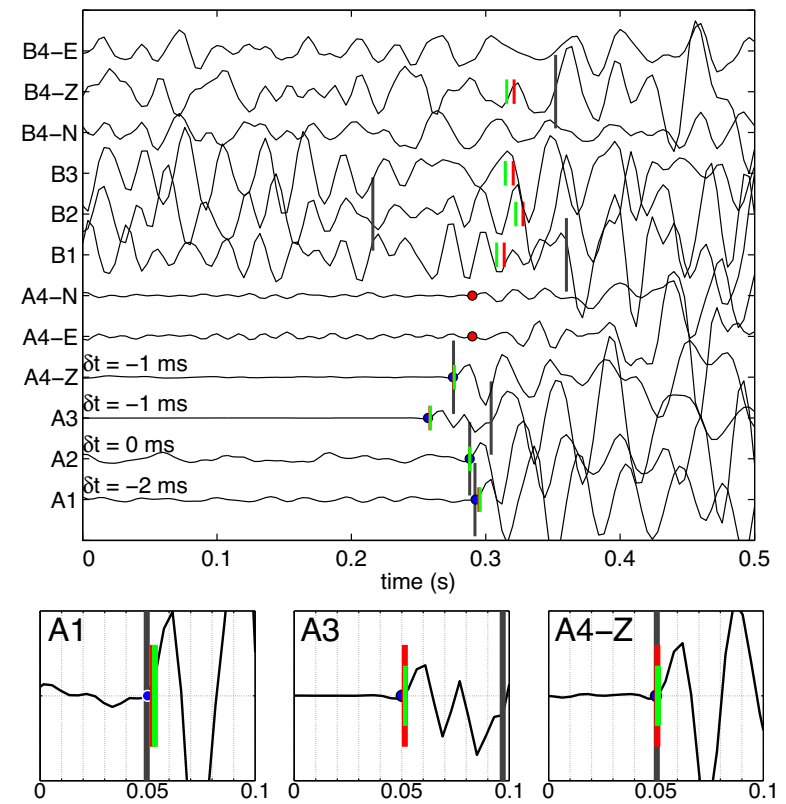

Shot 13
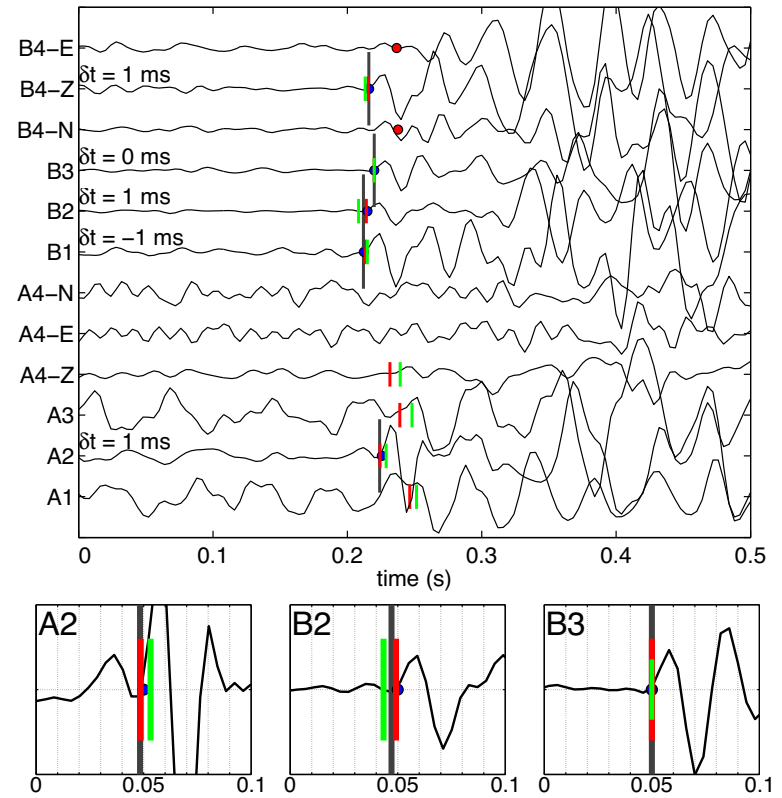

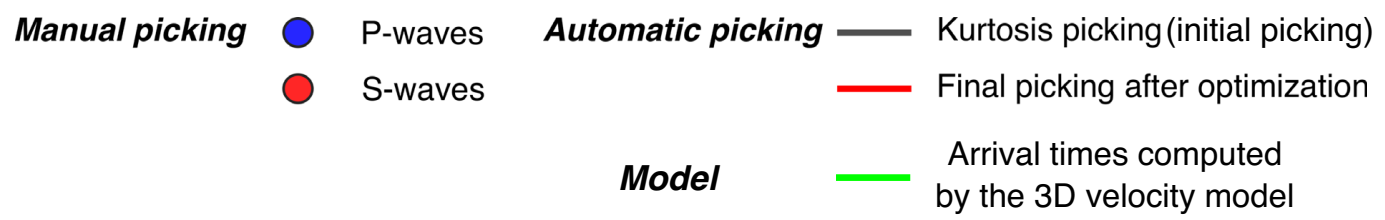

Figure 10. Comparison of the $P$-wave pick (i.e. manual, Kurtosis and the final picking obtained after the optimization) for shots 1 , 4 , 12 and 13 . The $S$-wave time arrivals are plotted on the horizontal traces. The arrival times computed with the 3-D velocity model are also presented.

the geometry of the network and the distance of the source to the seismic network. The SNR distribution poorly conforms to the attenuation law (regression coefficient of 0.84; Fig. 15b). However, this might be due to the heterogeneity of the attenuation coefficient in the landslide but also due to source mislocation. Indeed, numerous sources are located at the boundary of the grid search area. This may be explained by the use of a $P$-wave velocity model while rockfalls signals may be dominated by surface waves (Helmstetter 
(a)

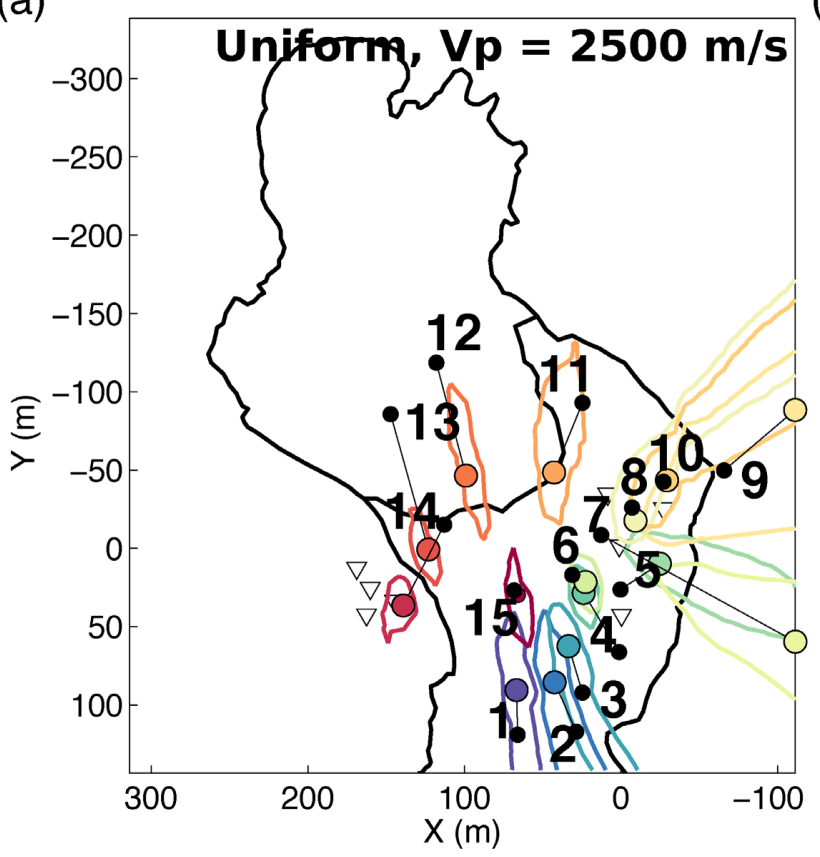

(b)

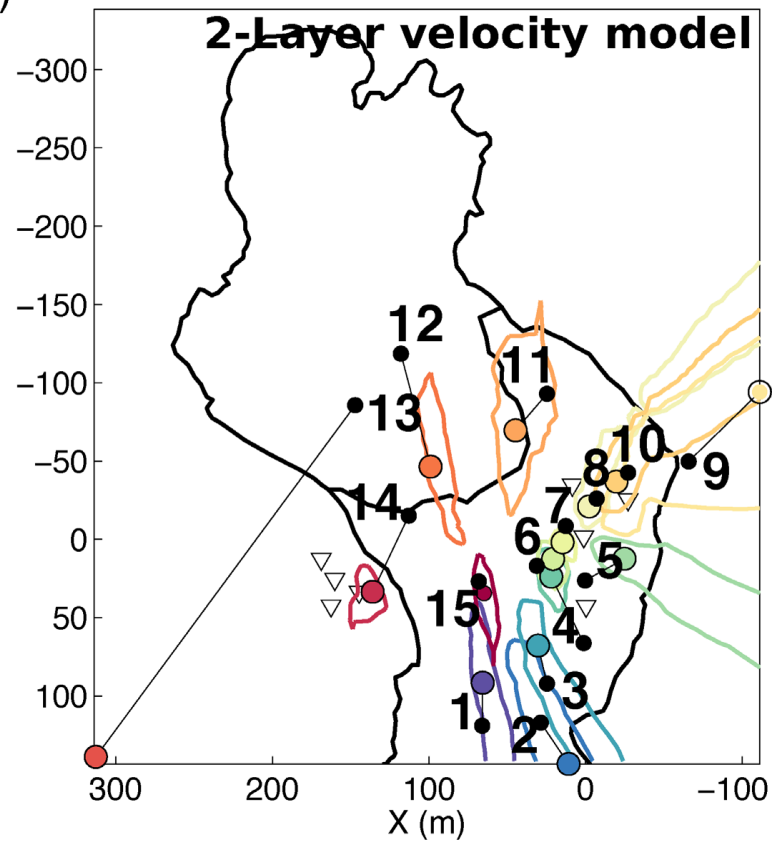

(c)

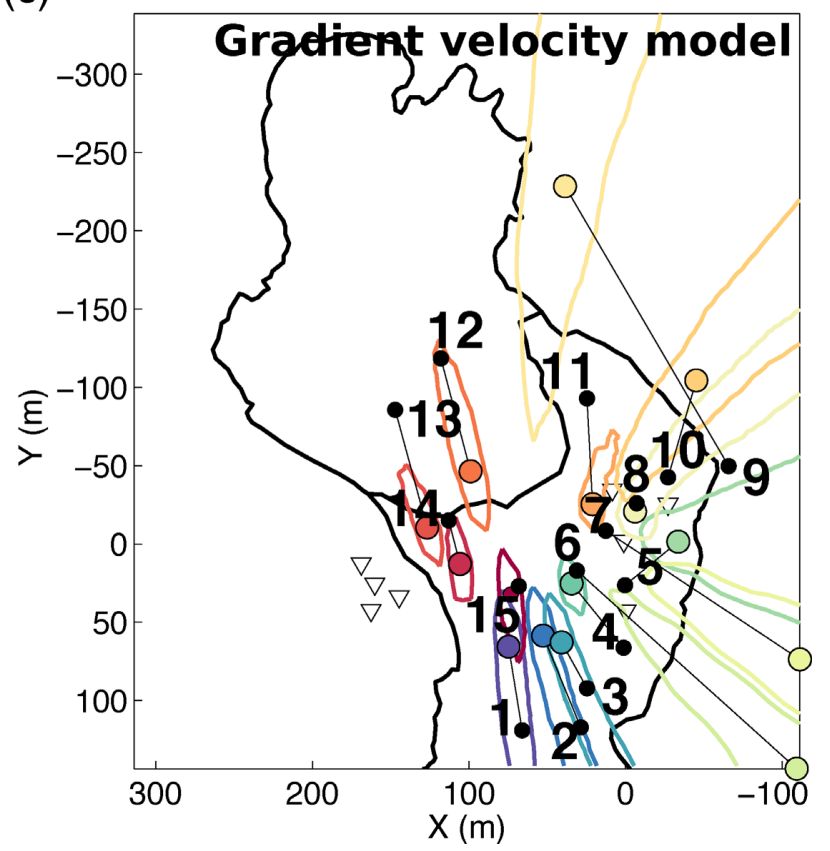

Figure 11. Location of the calibration shots with the $A P O L o c$ method using (a) a uniform velocity model taking into account the topography with $\mathrm{v}_{p}=2500 \mathrm{~m}$ $\mathrm{s}^{-1}$, (b) a two-layers velocity model composed of a superficial layer (above the bedrock limit) with a uniform velocity of $\mathrm{v}_{p}=800 \mathrm{~m} \mathrm{~s}$ and a deeper layer (bedrock ) with a uniform velocity of $\mathrm{v}_{p}=2500 \mathrm{~m} \mathrm{~s}^{-1}$ and (c) a gradient velocity model where the velocity in the superficial layer varies linearly from $\mathrm{v}_{p}=$ $800 \mathrm{~m} \mathrm{~s}^{-1}$ at the surface to $\mathrm{v}_{p}=2500 \mathrm{~m} \mathrm{~s}^{-1}$ in the bedrock.

\& Garambois 2010; Lacroix \& Helmstetter 2011; Hibert et al. 2014) especially when they occur at large distances from the sensors. A 3-D velocity model for surface wave propagation would probably be more adequate for the location of this kind of signals. A cluster of seismicity is also located in the vicinity of the seismic array B. This cluster may be explained either by mislocation of the sources or by the fact that numerous small rockfalls may occur at close distance $(<10 \mathrm{~m})$ of these sensors whereas only rockfall emitting large energy are recorded at large distances $(>10 \mathrm{~m})$. Some locations are coherent with the geomorphological observations. In particular, on the main scarp where all location are correlated to the rockfall paths (Fig. 14). The secondary scarp at the East appears to be also active (Fig. 14), which is in agreement with previous observations (Stumpf \& Kerle 2011; Stumpf et al. 2014). A better discrimination between rockfalls dominated by emergent surface waves and rockfalls with impulsive onsets may also improve the determination of the rockfall location and enable to select adequate velocity model $(P$ waves or surface waves) to locate each type of signal. The current catalogue 
(a)

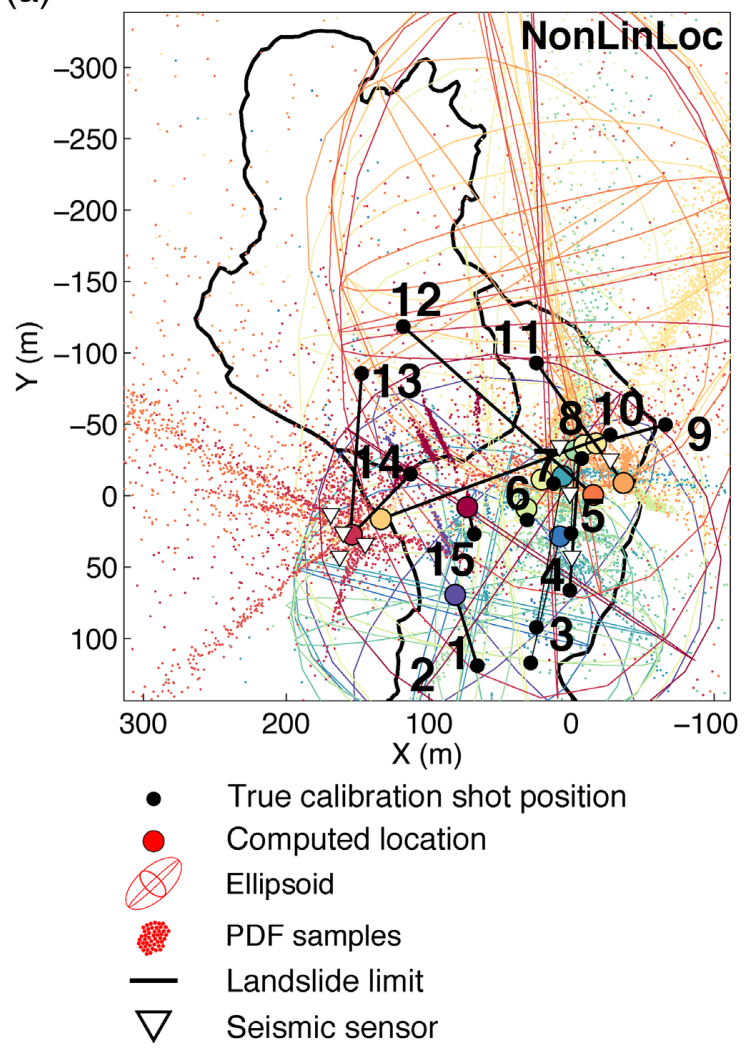

(b)

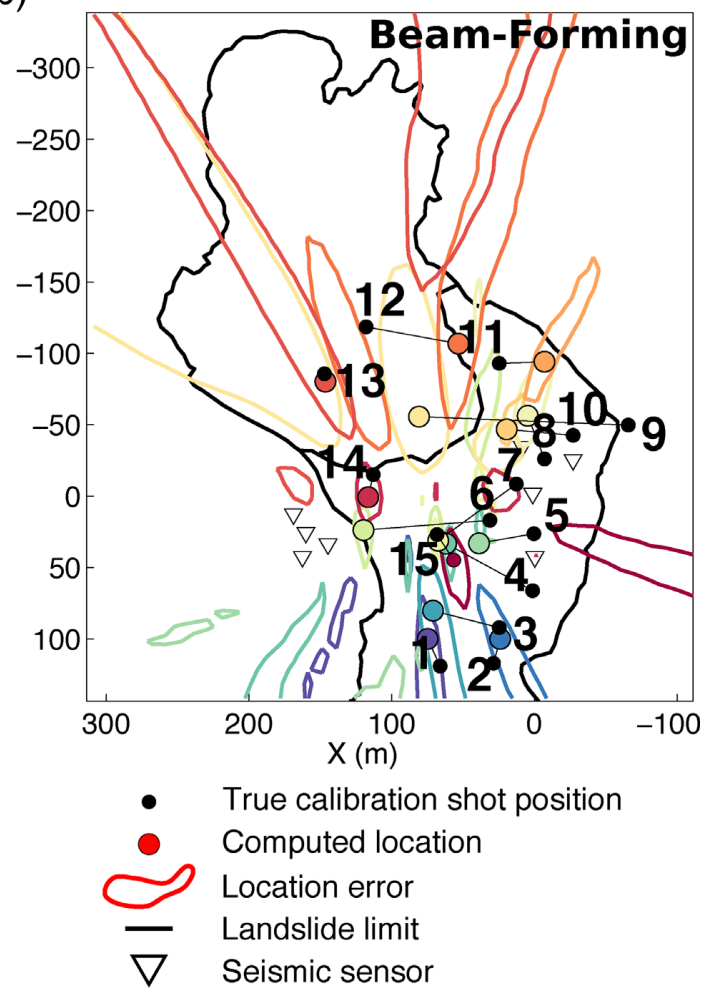

Figure 12. Location of the calibration shots withAPOLoc using (a) the L2-RMS likelihood function implemented in NonLinLoc and (b) the Beam-Forming approach. The location errors are represented by PDF samples and the 68 per cent confidence ellipsoids for locations (a) and by the contour delimiting the area where the correlation function is larger that 95 per cent of the maximal correlation (i.e. $C>0.95 C_{\max }$ ) for locations (b).

does not take into account this difference. Moreover, the polarization of the $P$ waves is expected to be complex and seems to be different for different location of the seismic sensors (Fig. 5). This would imply that the use of vertical sensors is not always adapted to pick the $P$ waves arrivals for rockfalls. We did not investigate the polarization of all the sources present in the catalogue. The development of robust and possibly automatic methods to estimate the nature of the first onset is needed to choose adequately the velocity model.

\subsection{Estimation of the depth of the sources}

The depths of the sources are currently not computed. In the synthetic tests, reasonable vertical errors $(3 \pm 3 \mathrm{~m})$ are obtained when no picking error are added to the simulated traveltimes for the velocity model (Appendix A). This case is highly unrealistic. The synthetic tests indicate that the uncertainty on the depth is large and very sensitive to the velocity models and picking errors taking into account the small thickness of the landslide (e.g. mean depth to the bedrock interface of $20 \mathrm{~m}$ ). The installation of buried sensors would improve the determination of the depth of the sources but their maintenance would be very difficult taking into account the high surface displacement rates (Malet et al. 2005). Further, the geometry of the seismic network is imposed by topographic and geomorphological constraints (e.g. elongated shape of the landslide, absence of stable parts within the landslide body, presence of lateral streams). One of the seismic arrays presents a wide aperture angle that reduces the precision of the azimuth inversion of the source. Installation of additional sensors in the north-south direction would improve the determination of the source epicentres and reduce the shape of the location error in that direction. One option is to install sensors at the top of the main scarp. This would improve the location of the rockfall events but would have only small impacts on the location of the slopequakes.

\subsection{Estimation of the attenuation coefficient}

We assumed a uniform coefficient of $\alpha=0.008 \mathrm{~m}^{-1}$. The inversion of the attenuation law found that a smaller coefficient of $0.002 \mathrm{~m}^{-1}$ fits the data for the calibration shots and even, that anelastic attenuation could be neglected for the slopequake locations. The uncertainties on the attenuation coefficients inverted from the calibration shots (Fig. 9) are also large: $-0.033 ;+0.038$ meaning that considering a uniform attenuation coefficient may be a too strong assumption. We thus inverted the attenuation coefficient for each shot (Table 2) and found very heterogeneous values ranging from 0.003 and $0.054 \mathrm{~m}^{-1}$ if we consider only the inversions with $R^{2}>$ 0.9 . The values are significantly larger than our initial assumption with a mean attenuation coefficient of $0.026 \mathrm{~m}^{-1}$.

The coefficient of regression varies also significantly. Very low coefficients of regression $(<0.9)$ are obtained for shots $1,6,9,12$, 13,14 and 15 . The attenuation coefficients of the shots on the eastern part of the landslide are less well resolved than for the shots of the western part. We investigated the possible site effects by analysing the ratio of the seismic amplitudes for 30 earthquakes coda Aki \& Chouet (1975). The amplification values range from 

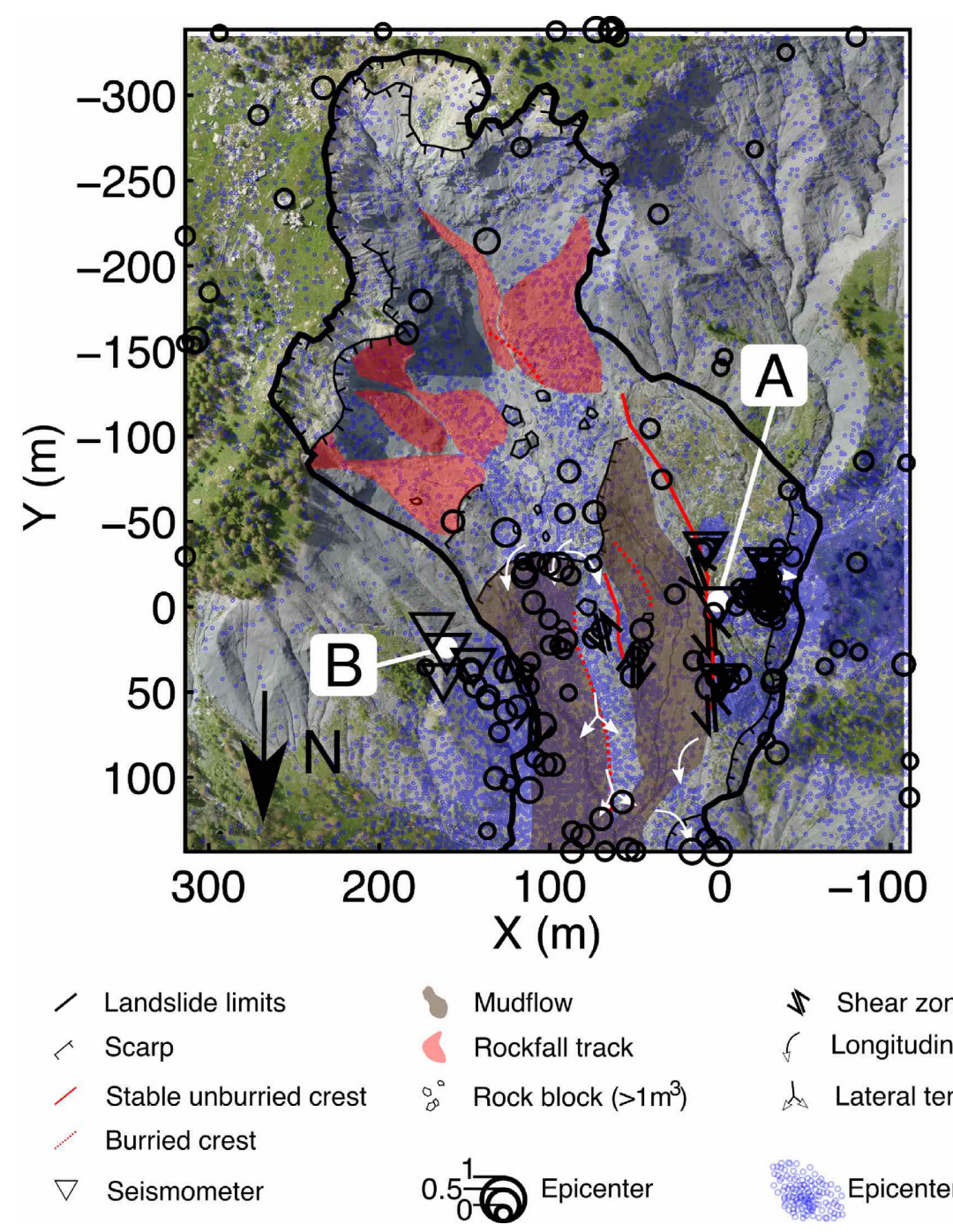

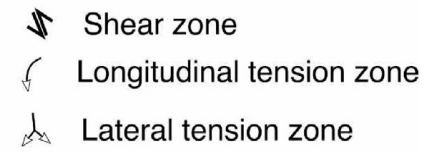

Epicenter error

Figure 13. Location of the slopequakes and spatial correlation with the geomorphological structures. The size of the circles represents the final value of the intertrace correlation. The map of the tension zones are reproduced after Stumpf et al. (2013).

0.8 to 1.5 . We obtained similar results by correcting the site effects. A possible explanation is thus that these shots are very distant from the two seismic arrays (minimal source to sensor distance $d_{\text {min }}$ $>60 \mathrm{~m}$ ) and are located at approximately the same distance to both sensors $\left(\mathrm{d}_{\max }-\mathrm{d}_{\text {min }}<100 \mathrm{~m}\right)$. The recorded amplitudes are in the same order and the attenuation coefficient cannot be constrained. We hence cannot confirm that the attenuation is larger in the eastern part of the landslide. Although our initial assumption provides proper estimation of the pre-location areas of the source, a possible improvement of the method would be to invert the attenuation coefficient in order to take into account the spatial heterogeneity (and possibly temporal variation) of this coefficient. Increasing the density of the network of sensors is also needed to improve the reliability of the attenuation coefficient inversion and to decrease the picking errors and uncertainties in particular for the distant sources.

\section{CONCLUSION}

The APOLOc methodology is based on an automatic picking of the first arrivals and on the optimization of the initial picking. A location is estimated at each step, and is progressively refined. The ASL method is used to identify a pre-location area to reduce the size of the grid search. A realistic $P$-wave velocity model is then introduced in the methodology. The location procedure is fully automatic and demonstrated good performance on calibration shots reducing by a factor of two the mean epicentre error $(27 \pm 29 \mathrm{~m})$ compared to other location strategies. In particular, the prior information from ASL and the iterative optimization of the initial Kurtosis picks improve the determination of the location. The picking procedure provides satisfactory results for strong and emergent onsets of natural sources occurring inside the seismic network. Even if the slopequakes present lower SNR than the calibration shots, their SNR distribution respects the attenuation law and the slopequakes seem to be reliably located. One may anticipate lower location errors of slopequakes for landslides developed in other geological contexts especially in hard rocks mostly due to lower attenuation of the $P$ waves arrivals. Despite the limitations linked to the seismic network geometry and the material heterogeneity, the results of APOLOC are promising. We show that simple (uniform) assumption on the velocity model and attenuation coefficient do not provide good estimation of the location. Further improvements would be to build a realistic model for surface waves propagation taking account the strong topography of the site and the lateral velocity heterogeneities, to invert 


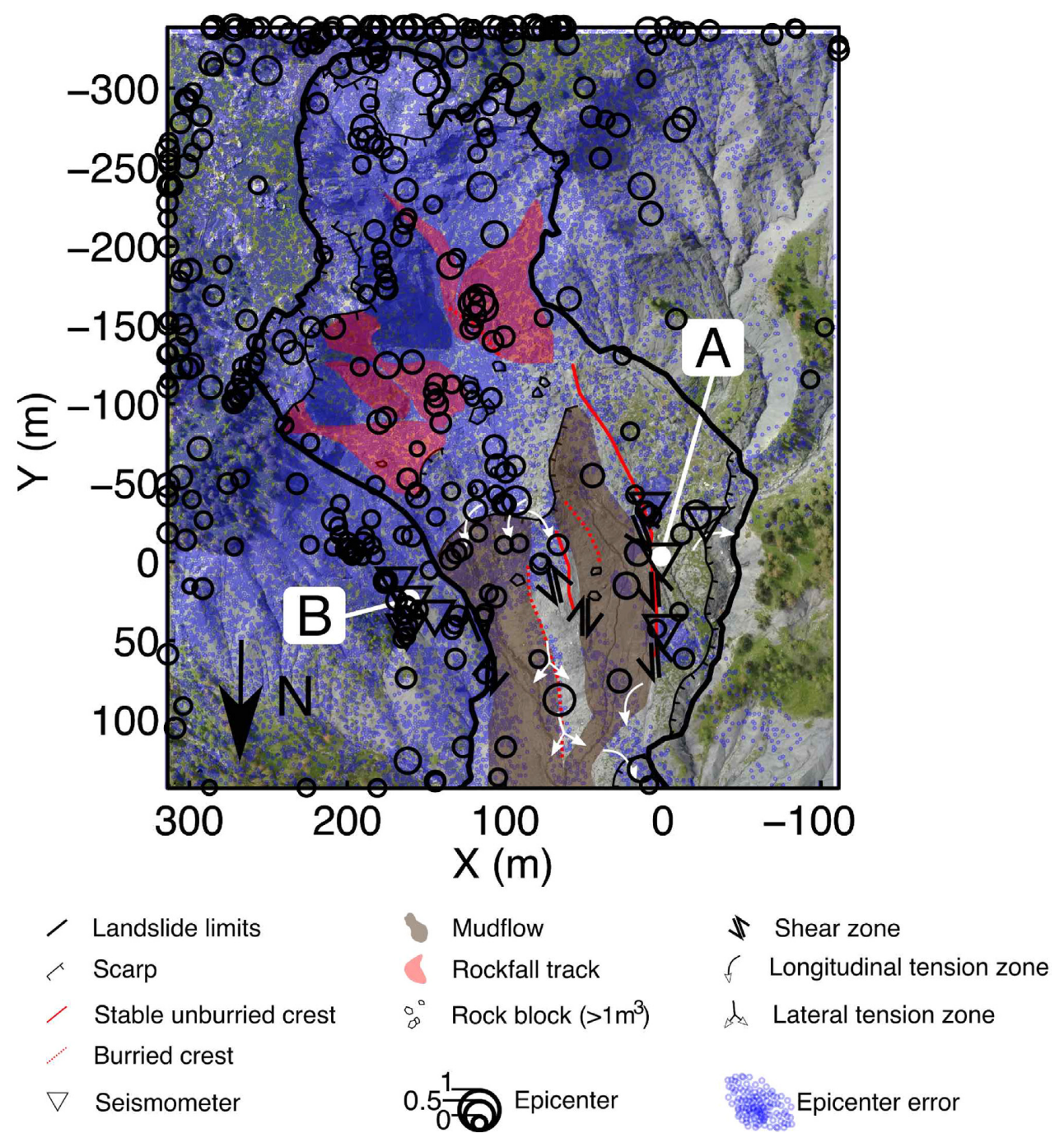

Figure 14. Location of the rockfalls and spatial correlation with the geomorphological structures. The size of the circles represents the final value of the intertrace correlation. The map of the tension zones are reproduced from Stumpf et al. (2013).
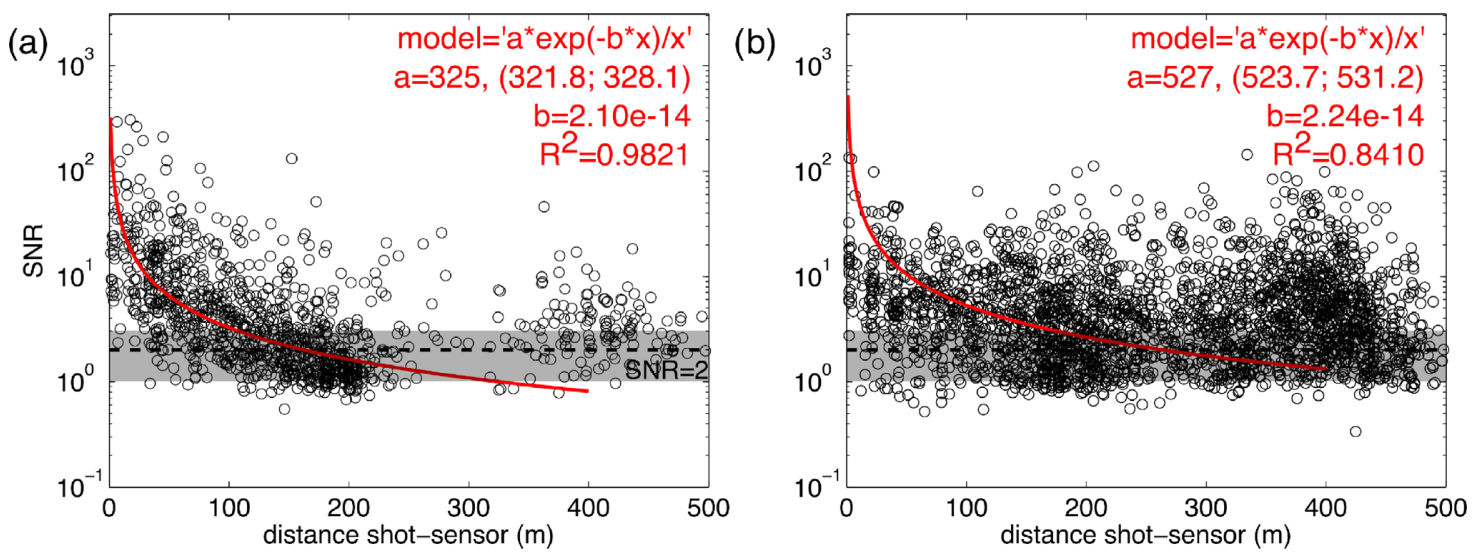

Figure 15. Signal-to-noise ratio (SNR) of the $P$ wave onset as a function of the source-sensor distance for (a) the slopequakes and (b) the rockfalls. The red curves represent the regression function best fitting the data. The equation of the model (f), the inverted coefficient with their upper and lower values and the regression coefficient are indicated in the upper right-hand corner of the plot with 'x' the source to sensor distance. 
Table 2. Inversion of the attenuation coefficient for each shots with the attenuation law: $A(x)=A_{0} \frac{e^{-\alpha x}}{\sqrt{x}}$. The minimum and maximum of the sensor to shot distances are indicated ( $\mathrm{d}_{\min }$ and $\mathrm{d}_{\max }$, respectively).

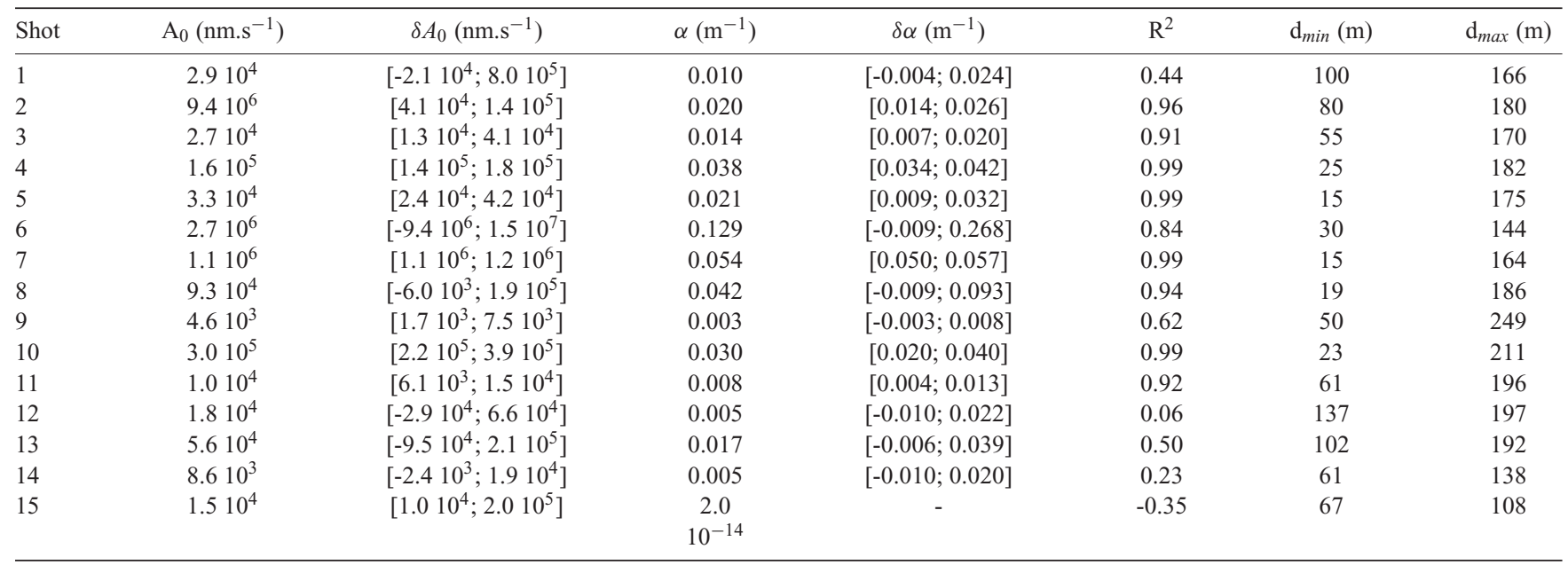

the attenuation coefficient and possibly implement joint inversion of the locations.

\section{ACKNOWLEDGEMENTS}

This work was carried with the support of the French National Research Agency (ANR) through the projects HYDROSLIDE 'Hydrogeophysical Monitoring of Clayey Landslides' and SAMCO 'Adaptation de la Société aux Risques Gravitaires en Montagne dans un Contexte de Changement Global' and of the Open Partial Agreement Major Hazards of Council of Europe through the project 'Development of cost-effective ground-based and remote monitoring systems for detecting landslide initiation'. The continuous seismic data were provided by the Observatoire Multidisciplinaire des Instabilités de Versant (RESIF/OMIV 2015). The authors acknowledge Alexandre Remaître, Pierrick Bornemann, Benoit Carlier, Juliette Trautmann and Gaëlle Rigoudy who participated to the seismic tomography campaign in 2014, and Patrice Ulrich who installed the permanent seismometers. Finally, the authors thank Clément Hibert for constructive discussions and comments on earlier versions of the manuscript, and Joan Gomberg (USGS) and an anonymous reviewer for their helpful comments.

\section{REFERENCES}

Aki, K. \& Chouet, B., 1975. Origin of coda waves: Source, attenuation, and scattering effects, J. geophys. Res., 80(23), 3322-3342.

Amitrano, D., Grasso, J.R. \& Senfaute, G., 2005. Seismic precursory patterns before a cliff collapse and critical point phenomena, Geophys. Res. Lett., 32(8), L08314.

Baillard, C., Crawford, W.C., Ballu, V., Hibert, C. \& Mangeney, A., 2014. An automatic Kurtosis-based P- and S-phase picker designed for local seismic networks, Bull. seism. Soc. Am., 104(1), 394-409.

Battaglia, J., Got, J.-L. \& Okubo, P., 2003. Location of long-period events below Kilauea volcano using seismic amplitudes and accurate relative relocation, J. geophys. Res.: Solid Earth, 108(B12), 2553.

Bernardie, S., Desramaut, N., Malet, J.-P., Gourlay, M. \& Grandjean, G., 2015. Prediction of changes in landslide rates induced by rainfall, Landslides, 12(3), 481-494.

Bottelin P. et al., 2014. Seismic and mechanical studies of the artificially triggered rockfall at mount néron (french alps, december 2011), Natural Hazards and Earth System Sciences, 14(12), 3175-3193.
Brückl, E., Brunner, F.K., Lang, E., Mertl, S., Müller, M. \& Stary, U., 2013. The Gradenbach observatory - monitoring deep-seated gravitational slope deformation by geodetic, hydrological, and seismological methods, Landslides, 10(6), 815-829.

Caplan-Auerbach, J. \& Huggel, C., 2007. Precursory seismicity associated with frequent, large ice avalanches on Iliamna volcano, Alaska, USA, Journal of Glaciology, 53(180), 128-140.

Carrière, S.R. et al., 2018. Rheological properties of clayey soils originating from flow-like landslides, Landslides, 15(8), 1615-1630.

Chouet, B.A., Page, R.A., Stephens, C.D., Lahr, J.C. \& Power, J.A., 1994. Precursory swarms of long-period events at redoubt volcano (1989-1990), alaska: Their origin and use as a forecasting tool, J. Volc. Geotherm. Res., 62(1), 95-135.

Crosta, G.B. \& Agliardi, F., 2003. Failure forecast for large rock slides by surface displacement measurements, Can. Geotech. J., 40(1), 176-191.

Gance, J., Grandjean, G., Samyn, K. \& Malet, J.-P., 2012. Quasi-Newton inversion of seismic first arrivals using source finite bandwidth assumption: Application to subsurface characterization of landslides, J. appl. Geophys., 87, 94-106.

García, A., Berrocoso, M., Marrero, J.M., Fernández-Ros, A., Prates, G., De la Cruz-Reyna, S. \& Ortiz, R., 2014. Volcanic alert system (VAS) developed during the 2011-2014 El Hierro (Canary Islands) volcanic process, Bull. Volcanol., 76(6), 825.

Gomberg, J., Bodin, P., Savage, W. \& Jackson, M.E., 1995. Landslide faults and tectonic faults, analogs?: The Slumgullion earthflow, Colorado, $\mathrm{Ge}$ ology, 23(1), 41-44.

Grandjean, G., Pennetier, C., Bitri, A., Meric, O. \& Mal+et, J.-P., 2006. Caractérisation de la structure interne et de l'état hydrique de glissements argilo-marneux par tomographie géophysique : l'exemple du glissementcoulée de Super-Sauze (Alpes du Sud, France), Compt. Rendus Geosci., 338(9), 587-595.

Helmstetter, A. \& Garambois, S., 2010. Seismic monitoring of Séchilienne rockslide (French Alps): Analysis of seismic signals and their correlation with rainfalls, J. geophys. Res.: Earth Surface, 115(F3), F03016.

Hibert, C. et al., 2014. Automated identification, location, and volume estimation of rockfalls at Piton de la Fournaise volcano, J. geophys. Res.: Earth Surface, 119(5), 1082-1105.

Intrieri, E. \& Gigli, G., 2016. Landslide forecasting and factors influencing predictability, Nat. Hazards Earth Syst. Sci., 16(12), 2501-2510.

Jenatton, L., Guiguet, R., Thouvenot, F. \& Daix, N., 2007. The 16,000-event 2003-2004 earthquake swarm in Ubaye (French Alps), J. geophys. Res.: Solid Earth, 112(B11), B11304.

Lacroix, P. \& Helmstetter, A., 2011. Location of seismic signals associated with microearthquakes and rockfalls on the Séchilienne landslide, French Alps, Bull. seism. Soc. Am., 101(1), 341-353. 
Larose, E., 2017. Environmental seismology: What can we learn from ambient noise? J. acoust. Soc. Am., 141(5), 3527-3527.

Levy, C., Jongmans, D. \& Baillet, L., 2011. Analysis of seismic signals recorded on a prone-to-fall rock column (Vercors massif, French Alps), Geophys. J. Int., 186(1), 296-310.

Levy, C., Mangeney, A., Bonilla, F., Hibert, C., Calder, E.S. \& Smith, P.J., 2015. Friction weakening in granular flows deduced from seismic records at the Soufrire Hills Volcano, Montserrat, J. geophys. Res.: Solid Earth, 120(11), 7536-7557.

Lomax, A., Virieux, J., Volant, P. \& Berge-Thierry, C., 2000. Probabilistic Earthquake Location in 3D and Layered Models, pp. 101-134, Springer Netherlands.

Mainsant, G., Chambon, G., Jongmans, D., Larose, E. \& Baillet, L., 2015. Shear-wave-velocity drop prior to clayey mass movement in laboratory flume experiments, Eng. Geol., 192, 26-32.

Mainsant, G., Jongmans, D., Chambon, G., Larose, E. \& Baillet, L., 2012b. Shear-wave velocity as an indicator for rheological changes in clay materials: lessons from laboratory experiments, Geophys. Res. Lett., 39(19), L19301.

Mainsant, G., Larose, E., Brnnimann, C., Jongmans, D., Michoud, C. \& Jaboyedoff, M., 2012a. Ambient seismic noise monitoring of a clay landslide: toward failure prediction, J. geophys. Res.: Earth Surface, 117(F1), F01030

Malet, J.-P., 2003, Flow-like landslides in the clay-shales of Southeast France. Morphology, behaviour and hydro-mechanical modelling, Thesis, Université Louis Pasteur - Strasbourg I.

Malet, J.-P., Laigle, D., Remaître, A. \& Maquaire, O., 2005. Triggering conditions and mobility of debris flows associated to complex earthflows, Geomorphology, 66(1-4), 215-235.

Neuberg, J. \& Pointer, T., 2000. Effects of volcano topography on seismic broad-band waveforms, Geophys. J. Int., 143(1), 239-248.

Petley, D.N., 2004. The evolution of slope failures: mechanisms of rupture propagation, Nat. Hazards Earth Syst. Sci., 4(1), 147-152.

Petley, D.N., Higuchi, T., Petley, D.J., Bulmer, M.H. \& Carey, J., 2005. Development of progressive landslide failure in cohesive materials, Geology, 33(3), 201.

Podvin, P. \& Lecomte, I., 1991. Finite difference computation of traveltimes in very contrasted velocity models: a massively parallel approach and its associated tools, Geophys. J. Int., 105(1), 271-284.

Poli, P., 2017. Creep and slip: Seismic precursors to the Nuugaatsiaq landslide (Greenland), Geophys. Res. Lett., 44(17), 8832-8836.

Provost, F., Hibert, C. \& Malet, J.-P., 2017. Automatic classification of endogenous landslide seismicity using the Random Forest supervised classifier, Geophys. Res. Lett., 44(1), 113-120.

Provost, F. et al., 2018. Towards a standard typology of endogenous landslide seismic sources, Earth Surf. Dyn. Discuss., 2018, 1-44.

RESIF/OMIV, 2015. RESIF - Réseau Sismologique et Géodésique Français; OMIV - French Multidisciplinary Observatory of Slope Instabilities, http: //dx.doi.org/10.15778/resif.mt.

Rouse, C., Styles, P. \& Wilson, S., 1991. Microseismic emissions from flowslide-type movements in South Wales, Eng. Geol., 31(1), 91-110.

Saito, M., 1969. Forecasting time of slope failure by tertiary creep, in Proceedings of the 7th Int. Conf on Soil Mechanics and Foundation Engineering, Mexico City, 2, pp. 677-683, Citeseer.

Schmutz, M., Gurin, R., Andrieux, P. \& Maquaire, O., 2009. Determination of the 3D structure of an earthflow by geophysical methods, J. appl. Geophys., 68(4), 500-507.

Schöpa, A., Chao, W.-A., Lipovsky, B., Hovius, N., White, R.S., Green, R.G. \& Turowski, J.M., 2017. Dynamics of the askja caldera july 2014 landslide, iceland, from seismic signal analysis: precursor, motion and aftermath, Earth Surf. Dyn. Discuss., 2017, 1-34.

Spillmann, T., Maurer, H., Green, A.G., Heincke, B., Willenberg, H. \& Husen, S., 2007. Microseismic investigation of an unstable mountain slope in the Swiss Alps, J. geophys. Res.: Solid Earth, 112(B7), B07301.

Stump, A., Malet, J.-P., Niethammer, U. \&Rotmund., 2013. Image-based mapping of surface fissuress for the investigation of landslide dynamics, Geomorphology, 186, 12-27.
Stumpf, A., Malet, J.-P., Allemand, P., Pierrot-Deseilligny, M. \& Skupinski, G., 2015. Ground-based multi-view photogrammetry for the monitoring of landslide deformation and erosion, Geomorphology, 231, 130-145.

Stumpf, A.e. \& Kerle, N., 2011. Object-oriented mapping of landslides using Random Forests, Remote Sens. Environ., 115(10), 2564-2577.

Stumpf A. Malet, J.-P., Allemand, P. \& Ulrich, P., 2014. Surface reconstruction and landslide displacement measurements with Pléiades satellite images, ISPRS J. Photogram. Remote Sens., 95, 1-12.

Taisne, B., Brenguier, F., Shapiro, N.M. \& Ferrazzini, V., 2011. Imaging the dynamics of magma propagation using radiated seismic intensity, Geophys. Res. Lett., 38(4), L04304.

Tarantola, A. \& Valette, B., 1982. Generalized nonlinear inverse problems solved using the least squares criterion, Rev. Geophys., 20(2), 219-232.

Tonnellier, A., Helmstetter, A., Malet, J.-P., Schmittbuhl, J., Corsini, A. \& Joswig, M., 2013. Seismic monitoring of soft-rock landslides: the Super-Sauze and Valoria case studies, Geophys. J. Int., 193(3), $1515-1536$.

Travelletti, J. \& Malet, J.-P., 2012. Characterization of the 3D geometry of flow-like landslides: A methodology based on the integration of heterogeneous multi-source data, Eng. Geol., 128, 30-48.

van Asch, T., Malet, J.-P. \& van Beek, L., 2006. Influence of landslide geometry and kinematic deformation to describe the liquefaction of landslides: Some theoretical considerations, Eng. Geol., 88(1), 59-69.

Van Asch, T. W.J., 1984. Creep processes in landslides, Earth Surf. Process. Landforms, 9(6), 573-583.

Vilajosana, I., Suriñach, E., Abellán, A., Khazaradze, G., Garcia, D. \& Llosa, J., 2008. Rockfall induced seismic signals: case study in Montserrat, Catalonia, Nat. Hazards Earth Syst. Sci., 8, 805-812.

Vouillamoz, N., Rothmund, S. \& Joswig, M., 2017. Characterizing the complexity of seismic signals at slow-moving clay-rich debris slides: The super-sauze (southeastern france) and pechgraben (upper austria) case studies, Earth Surf. Dyn. Discuss., 2017, 1-34.

Walter, F., Burtin, A., McArdell, B.W., Hovius, N., Weder, B. \& Turowski, J.M., 2017. Testing seismic amplitude source location for fast debris-flow detection at illgraben, switzerland, Nat. Hazards Earth Syst. Sci., 17(6), 939-955.

Walter, M., Arnhardt, C. \& Joswig, M., 2012. Seismic monitoring of rockfalls, slide quakes, and fissure development at the Super-Sauze mudslide, French Alps, Eng. Geol., 128, 12-22.

Walter, M., Gomberg, J., Schulz, W., Bodin, P. \& Joswig, M., 2013. Slidequake generation versus viscous creep at softrock-landslides: Synopsis of three different scenarios at Slumgullion landslide, Heumoes slope, and Super-Sauze mudslide, J. Environ. Eng. Geophys., 18(4), 269-280.

Yamada, M., Mori, J. \& Matsushi, Y., 2016. Possible stick-slip behavior before the Rausu landslide inferred from repeating seismic events, Geophys. Res. Lett., 43(17).

\section{APPENDIX: SENSITIVITY ANALYSIS: LOCATION ACCURACY VS. SEISMIC VELOCITY MODELS AND PICKING ERRORS}

In order to quantify the influence of the velocity model and of the picking error on the location accuracy, 180 seismic sources are simulated with the NonLinLoc package. The synthetic sources are placed at nine different horizontal $(\mathrm{X}-\mathrm{Y})$ locations in the upper part of the landslide; their depths range from 0 to $20 \mathrm{~m}$ below the surface for each $(\mathrm{X}-\mathrm{Y})$ locations. The current configuration of the SuperSauze seismic network is used. Two tests are carried out in order to assess the sensitivity: (1) of the location for different velocity models and (2) of the location for different picking errors. For each tests, the synthetic $P$-wave arrival travel time tables computed with the 3-D $P$-wave velocity model are taken as the reference time $t_{0}(c f$. Section 3.1). It implies that for testing the velocity model influence, the location are estimated using the travel time tables of the tested 
(a)
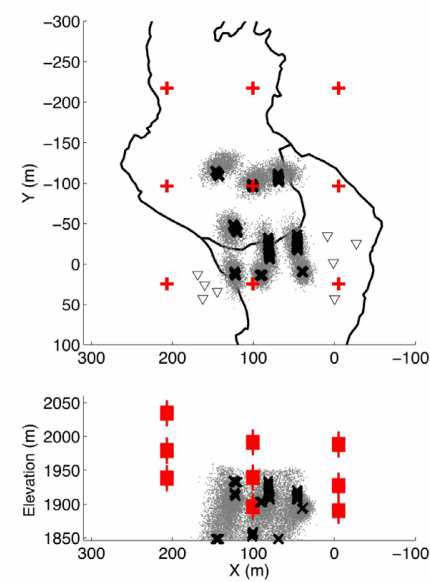

(c)
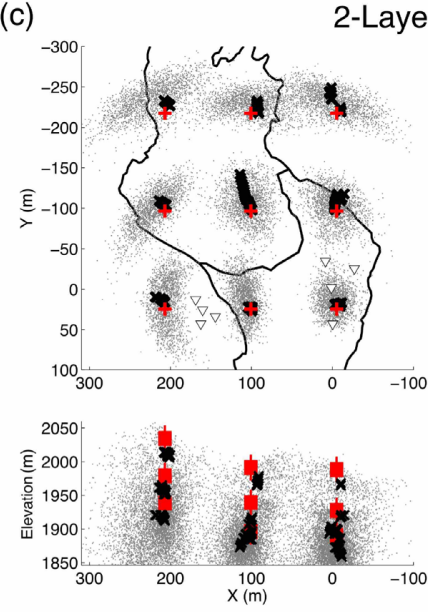

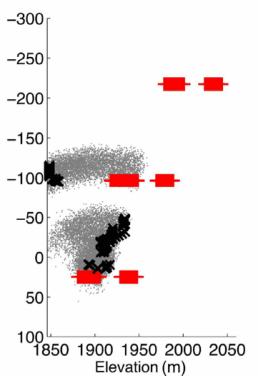

Elevation $(\mathrm{m})$

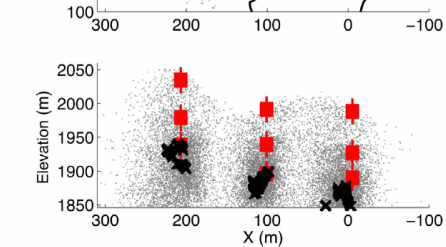

(d)

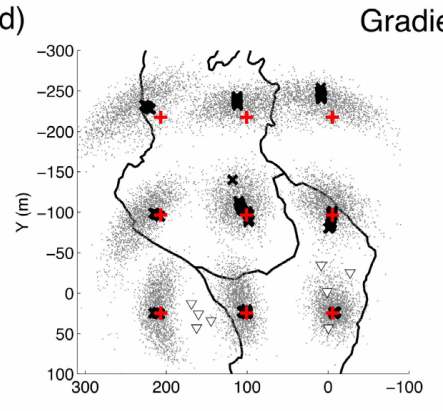

Gradient model

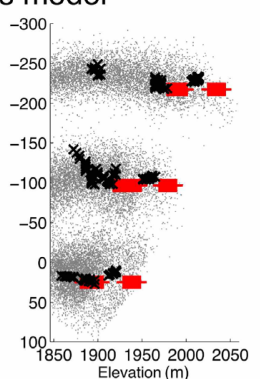

Elevation (m) (b)

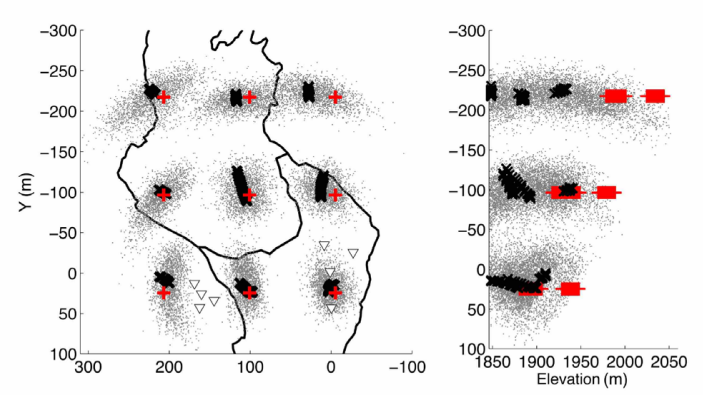

90019502000
Elevation (m)

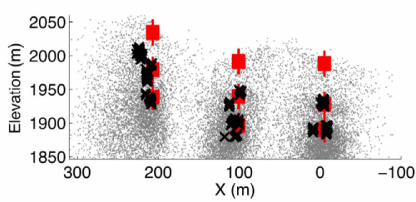

Figure A1. Influence of four velocity models on the location of synthetic sources: (a) homogeneous $P$-wave velocity model of $1500 \mathrm{~m} \mathrm{~s}^{-1}$; (b) homogeneous $P$-wave velocity model of $2500 \mathrm{~m} \mathrm{~s}^{-1}$; (c) two-layers velocity model with constant $P$-wave velocities of $1000 \mathrm{~m} \mathrm{~s}^{-1}$ in the landslide body and $2700 \mathrm{~m} \mathrm{~s}{ }^{-1}$ in the bedrock and (d) 'gradient' velocity model where the velocity varies linearly with depth from $500 \mathrm{~m} \mathrm{~s}^{-1}$ in the top unit to $2700 \mathrm{~m} \mathrm{~s}^{-1}$ in the bedrock. The L2-RMS likelihood function implemented in NonLinLoc is used to locate the synthetic events.

model to locate reference arrival times $t_{0}$. For testing the picking error influence, an error of picking $\delta t_{0}$ is added to the reference picked times $t_{0}$. The error of picking is randomly drawn from a Gaussian distribution centred at $0 \mathrm{~s}$ with a variance corresponding to the tested picking error magnitude. The location is computed with the reference 3 -D $P$-wave velocity model for the pick times $t$ $=t_{0}+\delta t_{0}$.

The locations are computed with the NonLinLoc package using the L2-RMS likelihood. The hypocentres are plotted by determining the maximum likelihood (computed from the L2-norm misfit between observed and calculated travel-times) and the location uncertainty (computed from the hypocentre Posteriori Density Functions -PDFs-). The PDF gives the probability of the source location considering the uncertainty on the data and the model. The point density of the PDF sample is proportional to the PDF value of the cell; thus the more dense the points are, the higher the PDF value is (Lomax et al. 2000). Consequently, robust source locations correspond to dense and narrow PDF samples.

\section{A1 Sensitivity to the seismic velocity model}

Four velocity models are tested: (1) a homogeneous model with a velocity of $1500 \mathrm{~m} \mathrm{~s}^{-1}$, (2) a homogeneous model with a velocity of $2500 \mathrm{~m} \mathrm{~s}^{-1}$, (3) a 2-layers velocity model with a velocity of $1500 \mathrm{~m} \mathrm{~s}^{-1}$ above the bedrock and $2700 \mathrm{~m} \mathrm{~s}^{-1}$ in the bedrock and (4) a gradient velocity model where the velocity increases from the surface $\left(v_{P}=600 \mathrm{~m} \mathrm{~s}^{-1}\right)$ to the bedrock interface $\left(v_{P}=2700 \mathrm{~m} \mathrm{~s}^{-1}\right)$. The homogeneous models are chosen as a low and high estimation of the apparent velocity of $P$ wave through the landslide. The synthetic source for $P$-wave arrival times are computed with the reference $3-\mathrm{D}$ velocity model presented in Section 3.1 and the location is 
(a)

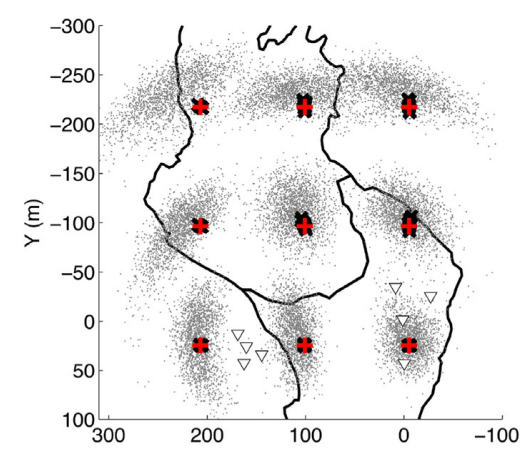

Picking error : $\pm 0 \mathrm{~ms}$

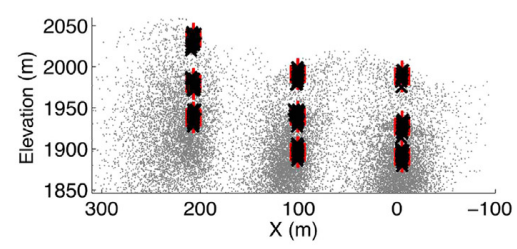

(c)

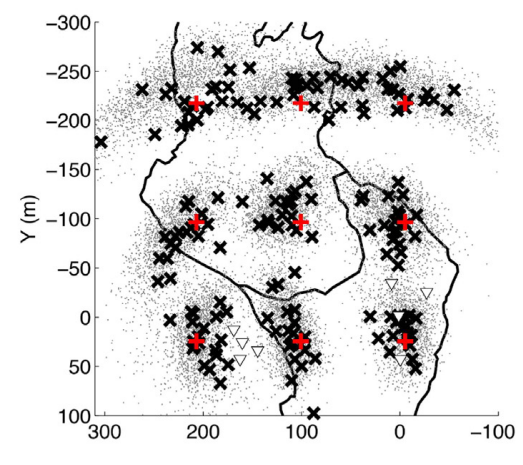

$$
\text { Picking error : } \pm 10 \mathrm{~ms}
$$
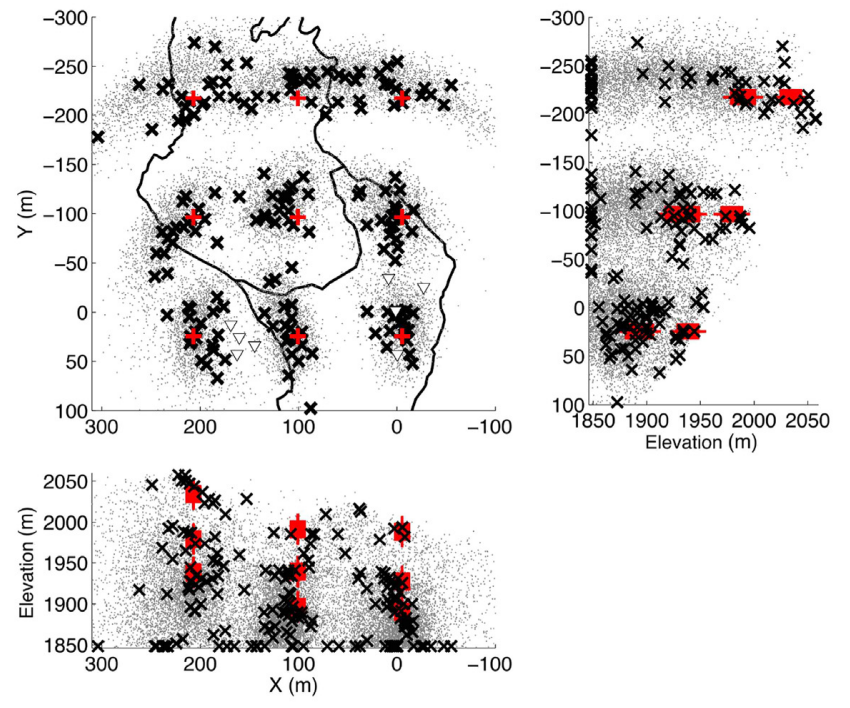

(b)

Picking error : $\pm 5 \mathrm{~ms}$
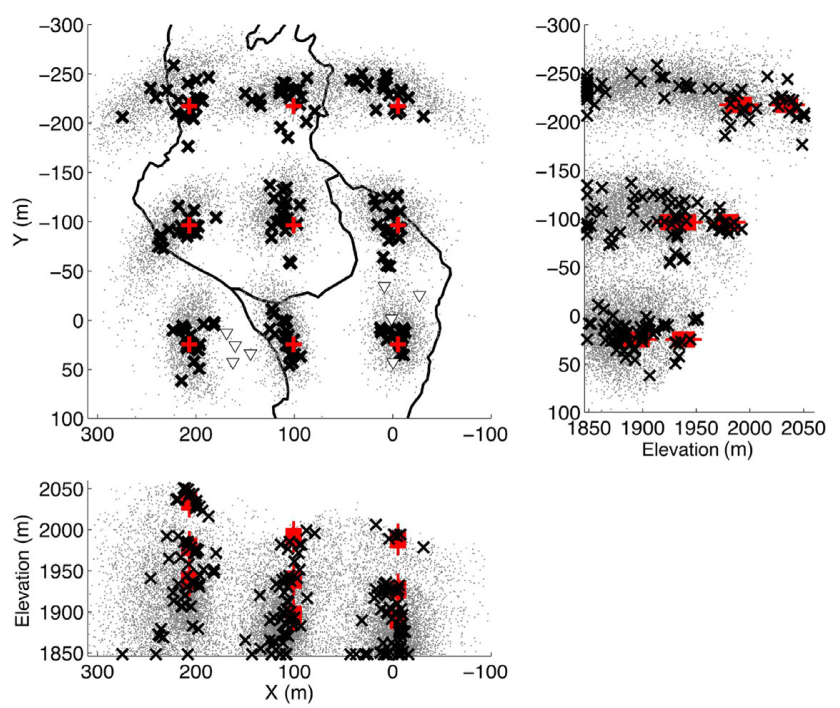

(d)

Picking error : $\pm 50 \mathrm{~ms}$
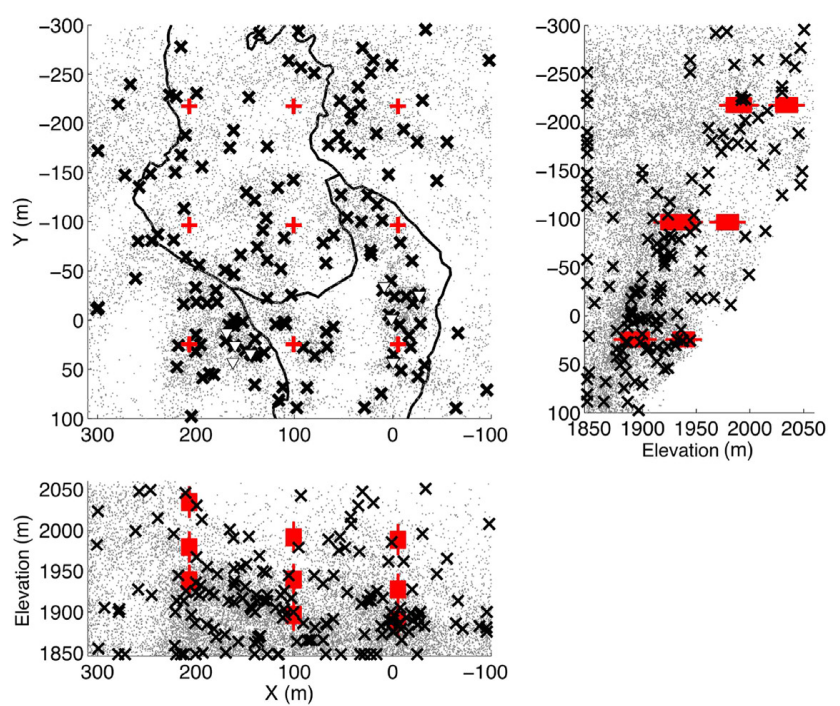

Figure A2. Influence of the picking error on the location of synthetic sources. Three picking error values are tested: (a) with no picking error; (b) \pm 5 ms; (c) $\pm 10 \mathrm{~ms}$; (d) $\pm 50 \mathrm{~ms}$. The L2-RMS likelihood function implemented in NonLinLoc and the 3-D velocity model is used to locate the synthetic events.

calculated for all the velocity models. The results of the location with the four different velocity models are plotted in Fig. A1.

The epicentre errors are larger (mean error $89 \mathrm{~m}$ ) with the first velocity model $\left(\mathrm{v}_{P}=1500 \mathrm{~m} \mathrm{~s}^{-1}\right)$ than with the other models (mean error 11-14 $\mathrm{m}$ ). The hypocentre errors are larger with a mean error of $115 \mathrm{~m}$ for the first model, $66 \mathrm{~m}$ for the second model $\left(v_{P}=2500 \mathrm{~m}\right.$ $\mathrm{s}^{-1}$ ) and $30 \mathrm{~m}$ for the 2-layers and the gradient models. The PDFs scatters of the location obtained for the first model are narrow with an extension of $c a .50 \mathrm{~m}$ in the horizontal plane and $100 \mathrm{~m}$ in depth.
The PDFs scatters obtained for other models have a larger extension of $c a .100 \mathrm{~m}$ in the horizontal plane and $c a .200 \mathrm{~m}$ in depth. Their shapes are elongated along the $Y$-direction for the sources located at the same latitude as the seismic sensors and at further distances progressively elongate in the $X$-direction. In comparison, when the locations are calculated with the 3 -D velocity model, the hypocentre errors decrease to $2 \mathrm{~m}$ (Fig. A1a) but the shapes of the PDF scatters are similar to the ones obtained with the homogeneous velocity model $\left(v_{P}=2500 \mathrm{~m} \mathrm{~s}^{-1}\right)$, the 2-layer and the gradient models. 
The latter can be considered as reliable approximation of the 3-D velocity model.

\section{A2 Sensitivity to the picking errors}

The arrival times of the synthetic sources are computed with the reference $3-\mathrm{D}$ velocity model (Fig. A2) and random picking errors of $\pm 0, \pm 5, \pm 10$ and $\pm 50 \mathrm{~ms}$ are added to the arrival times, respectively. The locations are computed with NonLinLoc using the L2-RMS likelihood and the results are presented in Fig. A2.
The mean epicentre and hypocentre errors progressively increase with the picking error (mean horizontal error of $3 \pm 2,20 \pm 13$, $29 \pm 21$ and $117 \pm 94 \mathrm{~m}$ and mean vertical error of $3 \pm 3,46 \pm 45$, $58 \pm 49$ and $131 \pm 98 \mathrm{~m}$ for the $\pm 0, \pm 5, \pm 10$ and $\pm 50 \mathrm{~ms}$ added error, respectively). The PDF scatters present similar shapes as the ones described in Section 4.1.1 when the picking error is lower than $10 \mathrm{~ms}$. For a picking error of $\pm 50 \mathrm{~ms}$, the PDF scatters is widely spread and diffused and the source locations are poorly constrained. 